\title{
The political economy of the disability insurance: theory and evidence of gubernatorial learning
}

Radha lyengar ${ }^{* *}$ and Giovanni Mastrobuoni $2,3,4,5$

\section{*Correspondence:}

gmastrob@essex.ac.uk

${ }^{1}$ National Bureau of Economic

Research, London School of

Economics, London, UK

Full list of author information is

available at the end of the article

\section{Springer}

\begin{abstract}
The dramatic rise in the disability insurance (DI) rolls in the last 20 years has been the subject of much controversy. While the relationship between DI and labor force participation has been the subject of a growing literature, the mechanism of this transition from employment to DI remains unclear. We hypothesize that one mechanism is the state-level administration of the program which creates a classic principal-agent problem. We analyze the conflict of interests for Disability Determination Services agencies between Social Security Administration (SSA) standards and state gubernatorial political interests interacted with the increased demand for disability insurance as an alternative for low-skilled employment during the period of 1982 to 2013. We find evidence that multi-term governors allow a greater fraction of applicants than do first-term governors, but only up to year 2000, when allowance rates started to decrease over time. We develop a model that illustrates how these differences can be due to the type of monitoring conducted by the SSA. We provide additional evidence supporting this hypothesis analyzing how the effects interact with economic and political constraints.
\end{abstract}

JEL codes: H55, I18, I38, G22

Keywords: Disability insurance; Principal-agent; Social security administration; Monitoring

\section{Introduction}

The dramatic rise in disability insurance rolls (DI from now on) in the last 20 years has been the subject of much controversy in both popular and academic circles. Both theory and empirical evidence have found what appears to be labor market consequences from the expansion of DI but with the general assumption that marginally able individuals are able to enter DI when they are unable to find employment with a sufficiently high wage. From this assumption arises the question of whether the administrators of DI are simply attempting to expand DI enrolment during times of economic hardships or lack the evidence to distinguish between the increased number marginal candidates who arrive economic downturns.

The structure of the disability system establishes conflicting incentives for states and the Social Security Administration (SSA). Unlike the federal government, which has an incentive to cost minimize by reducing caseloads, state governors have an interest in

(c) 2014 lyengar and Mastrobuoni; licensee Springer. This is an Open Access article distributed under the terms of the Creative Commons Attribution License (http://creativecommons.org/licenses/by/2.0), which permits unrestricted use, distribution, and reproduction in any medium, provided the original work is properly credited. 
increasing them. This is for two reasons. First, if individuals applying for DI are denied they may apply for other forms of social welfare for which states bear the cost. To the extent that governors seek to cost-minimize with respect to their own social programs, they will attempt to admit more marginally disabled individuals into the federal DI program. Second, the removal of these individuals from the ranks of the unemployed may allow a change in the perception of state level economic performance. This could affect the governor's political capital or re-election prospects.

This study uses several facts about the DI program administrative procedure to determine the role political gaming by governors may play in expanding disability rolls: the inherent principal-agent tension from the federal-funding, state-administration structure; the political gains for governors from lower unemployment rates; and, the lack of oversight in program administration.

Principal-agent Issues Any scholars have noted, there is an inherent principal-agent issue in the administration of DI because it is fully federally funded but entirely stateadministered. By law, disability determinations are made by state agencies under contract with the Social Security Administration. The head of this agency, the director of Disability Determination Services (DDS), is appointed by the governor and the staff of this agency is comprised of state employees. This naturally generates a conflict of interest for these agencies which depend on the federal government for funding, but remain under the administrative and political direction of state governors. DDS caseworkers are well aware of the various incentives. A DDS state director claimed that he "would probably be discharged if he followed a strict interpretation of SSA guidelines" (United States General Accounting Office 1978; Berkowitz 1987). Disability examiners follow such sentiments. According to the same source one examiner claimed, "We are state employees; therefore, we don't have to pay attention to what the SSA regional office ... or any other federal agency says" (United States General Accounting Office 1978).

Moreover, in a series of studies Keiser $(1999,2001,2010)$ presents evidence about this principal-agent problem. Her 2001 study shows that state bureaucrats reduce access to the disability federal program when state governments incur costs associated with those programs, especially under conditions of fiscal stress. In a recent survey of DDS examiners, Keiser (2010) finds that examiners who believe that DDS offices should be most accountable to federal taxpayers have lower allowance rates (about 6 percent) than those who believe DDS offices should be most accountable to citizens in their state ${ }^{1}$.

Political gains for governors The observed link between unemployment rates and gubernatorial popularity suggests that governors may have a strategic interest in reducing, or appearing to reduce, the unemployment rate ${ }^{2}$. Recent work by Wolfers (2007) puts a finer point on this, illustrating that voters systematically make attribution errors regarding responsibility for negative economic conditions. Thus governors may face political fallout for economic conditions and may wish to use any mechanisms at their disposal to improve the welfare and economic well-being of their constituents. Moreover, admission into DI depends on the presentation of evidence that a worker is unable to work. Such evidence often involves evidence of injury or illness related pain, which may be difficult to assess and document by non-specialists; doctors typically provide evidence. The type 
of doctor and the nature of evidence that is sufficient to determine disability can vary the cost and difficulty in receiving and continuing to receive disability benefits.

Lack of oversight The SSA during this period had very little direct oversight and only period reviews. Later reforms would increase oversight but during significant periods of time, there was little monitoring by the principal (in this case, SSA), reducing the risk of detecting or deterring politically gaming allowance rates.

Taken together the difficult in observing many disabilities and the political incentives to reduce unemployment suggests that governors, if sufficiently motivated, could expand disability rolls ${ }^{3}$. This would have been quickly observed and corrected, however, were it not for the lax monitoring and oversight by the SSA. Thus this paper addresses questions regarding the interaction between legal rulings, administrative procedures, and labor market participation. To what extent did the rise of subjective admission criteria allow political actors to influence DI enrolment? While evidence that the rise in disability occurred after the 1984 liberalization of DI policies is presented in Autor and Duggan (2003), the question of to what extent this is related to political motives is difficult to ascertain from aggregate trends. This is especially true for disability insurance which during many time periods appears to have been administered in largely uniform ways. To answer this question we therefore rely on the overlap in periods with greater discretion and the type of monitoring used by the SSA.

Using a simplified model of delegation, we illustrate that a lax monitoring process can allow governors with a preference for higher allowance rates to learn how much they can safely increase acceptance rates without consequences. Because this learning occurs over time, we can compare multi-term governors to single-term governors during the same time periods ${ }^{4}$.

We show that while DI rates began rising as early as 1984, multi-term and single term governors' rates did not begin to diverge until 1986, when the introduction of evidence from treating physicians (rather than SSA physicians) was allowed by a court ruling. The divergence continued to grow until 1993 when evidentiary standards on pain were tightened and closed almost entirely by 1996 when the SSA issued a set of unifying evaluation criteria. What role did this political influence on the disability determination process play in the growth of the disability program? We find evidence that during periods in which the returns to expansion are high, for example governors face unfavorable economic or fiscal conditions, the acceptance rates among multiple term governors is higher. We also provide some evidence that the differences we observe are due to a governor's learning rather than a selection mechanism by which governors with low allowance rates do not survive to later terms. We also show that our results are not driven by electoral cycles. Indeed, we don't find evidence that allowance rates follow electoral cycles.

During the mid-eighties to the mid-nineties, disability insurance acceptance rates rose nearly 15 percent. Our results suggest that at least 10 percent of that increase is due to the gubernatorial influence on the allowance rates. The influence appears to be stronger when allowance rates rise than when they fall. Starting in 2000, when acceptance rates started plummeting, gubernatorial influence seems to have ceased.

This paper thus provides an important contribution linking two strands of literature: on vote buying and on labor market effects of social welfare programs. In particular, previous work has documented that political pressure and institutional design can combine to 
impact the administration of government programs. The results of this paper thus corroborate a growing body of literature that highlights the importance of political institutions on the public expenditure decisions and the use of spending to "buy off" voters ${ }^{5}$. There is also substantial evidence regarding the impact of disability benefits on labor force participation in the United States and internationally ${ }^{6}$. While previous work has systematically documented both these issues, this paper provides a mechanism linking the outcome of individual decisions (i.e. to avoid work for sufficiently generous public welfare alternatives) and political mechanisms that facilitate such behavior. In this case, the steep rise in the number of individuals on disability insurance is clearly linked to the rising acceptance rates. This increased acceptance rate could only occur when governors had enough flexibility in determination processes to allow more marginally disabled individuals onto disability rolls. The results of this paper thus indicate an important potential mechanism that has been under-explored: the role of political institutions in facilitating issues of moral hazard and adverse selection in insurance, tax and public welfare provisions.

\section{Background information}

The Social Security Administration (SSA) provides income and medical benefits to individuals eligible for disability insurance under the Social Securities Act (1935) ${ }^{7}$. The provision of these benefits occurs through two programs:

- Social Security Disability Insurance (DI): Established under Title II of the Social Security Act, DI is a social insurance program. It is intended to protect workers who become disabled and therefore cannot (or at least cannot be expected to) work. Thus, DI eligibility requires workers to be previously employed ${ }^{8}$. After age 65 , DI benefits are converted to Old Age and Survivors Insurance (OASI).

- Supplementary Security Insurance (SSI): Established under Title XVI of the Social Security Act, SSI is means-tested, intended to protect individuals with limited income and assets who would not otherwise qualify for SSDI. SSI beneficiaries can continue to receive benefits past age 65 .

Both programs use the same health criteria to determine eligibility. The Social Security definition requires an "inability to engage in any substantial gainful activity by reason of any medically determined physical or mental impairment which can be expected to result in death or which has lasted or can be expected to last for a continuous period of not less than 12 months 9 ". "Substantial gainful activity" is defined as working on a regular and continuing basis and earning over $\$ 830$ a month (in 2005) ${ }^{10}$. The disability must be "demonstrable by medically acceptable clinical and laboratory diagnostic techniques". This restriction is not overly strict in part due to the liberalization of the DI program that occurred in 1984.

Among other issues, this liberalization relaxed many of the requirements that governed the determination process ${ }^{11}$. Thus the criteria for disability, while well-defined, are not completely objective and leave room for discretion in the determination process.

\subsection{Funding and administration}

A crucial aspect of the federal DI/SSI system is that it is federally funded but administered by the states, establishing conflicting incentives for both parties. This administration occurs through the Disability Determination Services (DDS) offices in each state. These 
offices are part of state governments and are typically headed by an individual appointed by the governor. This agency manages the disability insurance claims sent by the SSA field office.

This state-based administrative mechanism was originally established to facilitate coordination with existing state vocational rehabilitation agencies and to encourage physician acceptance and participation in the disability insurance program ${ }^{12}$. However, state management, subjective decision-making standards, and lack of federal oversight is believed to be responsible for the great deal of variation in the disability allowance rates. State agencies are required to follow the regulations set by the SSA, but there are relatively few federal requirements relating to their administrative practices. The agencies follow state established personnel policies with respect of such matters as salaries, benefits, and educational requirements; do their own hiring; provide most of the training for adjudicators; follow their own quality assurance procedures; and pay state-established reimbursement rates for purchase of medical evidence. This results in different training and administrative practices that affect the determination process.

Variation in training and practices is exacerbated by the increased subjectivity of the determination process. Court decisions as well as changing perceptions about what constitutes disability has resulted in a number of new policies that require individual judgment by those adjudicating disability applications. For example, all adjudicators are required to assess subjective factors such as the credibility with respect to allegations of pain and the weight that should be given to the opinion of a treating source ${ }^{13}$.

Variation in health status, occupational composition, and demographical characteristics across different states would naturally give rise to differences in allowance rates. Determining the source of such variation, however, is important because the administrative environment leaves DDS agencies vulnerable to the influence of state-level political considerations. Indeed the General Accounting Office (GAO) reports concern about the impact of politics on disability determinations given that all DDS employees were state employees working for an executive agency ${ }^{14}$.

\subsection{Legal history}

The large growth in both the application and enrolment into the federal disability insurance prompted a set of congressional legislative reforms in 1980 which formed the backbone of the federal government's effort to define the scope and limit the growth of DI. SSA was required to review a specified percentage of State Disability Determination services allowances. This allowed for partial or complete take over from a State Disability Determination services (DDS) the function of making disability determinations if the DDS fails to follow federal regulations and guidelines or if the state no longer wishes to make the determinations. Therefore this required the agency to make own-motion reviews of Administrative Law Judge (ALJ) decisions (as opposed to per request of an appellant). Most notably, the reforms also required continuing disability reviews (CDRs) of DI benefits for non-permanently disabled beneficiaries at least every three years. In order to define the scope of improvement, the Reform Act also incorporated an amendment that was based on SSA's policies on the evaluation of pain. The amendments also contained a number of provisions designed to 
encourage DI and SSI disability beneficiaries to return to work, including continuation of benefits while the beneficiary is in vocational rehabilitation, the disregard of certain work-related expenses, and facilitated reentitlement to benefits that were lost after returning to work. The new rules established the need for a standard of pain evaluation.

During the application and appeals process, medical evidence is critical to correctly identifying whether an individual can be categorized as "disabled". The procedures rely on evidence from three difference sources: the treating physician, a consulting examiner, and a medical advisor. The weight given to the treating physician evidence relative to the other two sources may determine case outcomes but until 1991 was not uniformly applied to disability determinations (Schneider 1996). This formulation, often left ambiguous by the courts, could then be set at the state level permitting greater variation in the evidence provided by the individual's treating physician, which was generally thought to increase the likelihood of acceptance. This is because increased weighting of physician testimony allows the increased weight of subjective measures of pain and injury which treating physicians may testify to but government sponsored doctors (such as consulting examiner or medical advisor) may be unable to observe. The weighting of this testimony became an issue of contention between the SSA and the federal courts for almost 15 years. During that time period, changes in the boundaries of SSA authority as well as the rights of disability applicants and recipients generating changing standards of evaluation during the application and appeals process.

Based on divergence and later convergence in administrative rules regarding the weight to treating physician testimony there are three distinct periods of rules: 1982-1985, 1986-1992, and 1993-1996.

\subsubsection{Period 1 (1982-1985): uniform standards on evidence of pain after 1980 reforms}

Despite the 1980 legislation, a large number of newly denied or failed continuation cases were being returned to DI by the courts. The reports of the Ways and Means and Finance Committees on the 1980 amendments encouraged the courts to conform to new legislative standards. Given the response of the Ninth Circuit Court of Appeals ${ }^{15}$ and the sense that "the review process mandated under the 1980 amendments. . .resulted in some significant problems and dislocations which were not anticipated and which contributed to an unprecedented degree of confusion in the operation of the program", Congress passed the Disability Benefits Reform Act of 1984 (P.L. 98-460). The Disability Benefits Reform Act increased the evidential requirement necessary to demonstrate improvement and ability to work as grounds to terminate benefits. This act also wrote into the law for a temporary period SSA's criteria for evaluating pain and required the consideration of the cumulative effect of multiple disabilities. This increased the allowance rate for applicants with common musculoskeletal conditions (i.e. back pain and arthritis).

The importance of physician testimony arose in 1980 with the legislative change and was then heightened by the 1984 reforms. However, while the 1984 reforms formally relaxed previous standards, in practice it simply brought the administrative rules from SSA into agreement with the Circuit courts nationwide. Rather than the 1984 legislative reforms, this study uses two changes regarding the inclusion of treating 
physician evidence on pain and injury, which increased the state DDS discretion even further. While this issue is subtle, its potential for altering determinations is quite significant.

\subsubsection{Period 2 (1986-1992): variation in legal standards on evaluation of pain and physician testimony}

The second period was initiated when the Second Circuit Court of Appeals (in Schisler v. Heckler) stated that a treating physician's opinion on the subject of medical disability is binding unless contradicted by substantial evidence. Despite the fact that the Supreme Court upheld the SSA determination procedures in Bowen v. Yuckert (1986) this increased the DDS's discretion even further, and introduced increased confusion about the 1984 SSA guidelines.

This restriction prompted a second effort to reduce state discretion and generate uniformity. In 1988, SSA issued a new ruling on pain which restated the existing policy in the 1984 amendments. But again, several courts did not conform to such rulings. During this time period, four circuits were extremely vocal in their condemnation of the SSA standards and the unwillingness of the SSA to acquiesce to previous court rulings: the Second Circuit (NY, CT, VT), the Fourth Circuit (MD, WV, VA, NC, SC), the Eight Circuit (ND, SD, NE, MN, IA, MO, AR) and the Ninth Circuit (MT, ID, NV, AZ, CA, OR, WA, AK, HI). The opposition to the SSA mean states in the more controversial Circuits faced increased scrutiny and even legal review of DDS decisions. Thus inadvertently, these Circuit court stances on SSA administrative authority generated de facto variation in the extent of monitoring on disability determinations ${ }^{16}$.

\subsubsection{Period 3 (1993-1996): unification and training on SSA standards}

The tide turned in 1993, the Second Circuit Court of Appeals in Schisler v. Sullivan found that SSA's 1991 regulations on the opinions of treating physicians, while they departed in some ways from the court's earlier opinion, were a valid use of the agency's regulatory power. Finally in 1996 SSA issued a set of nine Social Security rulings commonly called process unification rulings and provided training on the rulings for all disability adjudicators. The subjects of the rulings included the weight to be given to treating source opinions and other medical opinions, the evaluation of pain and other symptoms, the assessment of credibility and residual functional capacity, and the application of federal court decisions. Thus after 1993, the uncertainty was ended and a uniform treatment across DDSs of pain evaluation and treating physician testimony was returned. But a reduced uncertainty did not reduce potential discretion, as shown by the constant growth of awards for mental and musculoskeletal diagnosis types. Such disorders represented about 30 percent of the awardees in 1982, 40 percent 10 years later (1992), and almost 50 percent 20 years later (2002) (U.S. Social Security Administration).

\subsection{Monitoring and oversight by the SSA}

The major shift toward treating physician testimony and subjective evidence of pain was thus introduced by various legislative changes and court rulings in 1984, and continued through 1996. While the relaxation and later constriction of such subjectivity 
would be less problematic if the SSA administered the programs, the independence of state-administered DDS was compounded by the relatively lax oversight and monitoring provided by the SSA.

Prior to 1972, SSA conducted pre-effectuation review (PER) of all DDS decisions. In 1972, the federal review of DDS decisions was drastically reduced to a national sample of five percent, conducted after the decision becomes effective. In 1980, Congress established the Pre-Effectuation Review (PER) giving SSA the authority to review a certain percentage of DDS decisions before they were paid. PER required a review of 15 percent of Title II (DI) and concurrent (DI/SSI) allowances in 1980, 35 percent in 1982, and 65 percent in 1983 and beyond. Today, the PER sample is a sample of 50 percent of all Title II (DI) and concurrent Title II/XVI (DI-SSI) initial allowances prior to effectuation of payment. Of the 50 percent of cases selected for review, 45 percent are targeted based on the profile and 5 percent are randomly selected (these are the Title II and concurrent Title II/XVI initial and reconsideration allowances selected for a quality assurance review). PER is mandated by law and has been updated to identify and sample the most error-prone cases for review.

In addition to the PER, the 1980 Social Security Amendments also gave SSA authority to set performance standards for DDSs with the option of taking over DDS workloads, if they failed to meet those standards. The 1980 Amendments also mandated that non-permanent disability cases must be reviewed every three years (CDRs). As a result of the 1980 Amendments, SSA established a DDS performance accuracy threshold of 90.6 percent combined accuracy rate for initial allowances and denials and began undertaking quality assurance reviews (QARs). The 90.6 percent level was somewhat arbitrarily chosen, based on the fact that it represented one and one-half standard deviations from the mean accuracy rate at that time. If a state DDS initial allowance or denial accuracy falls to 90 percent or less, sampling of the deficient stratum is increased to 140 cases per quarter (reduced from 196 in May, 2000) and remains at that level until the accuracy rate improves ${ }^{17}$. In addition, the SSA requires that DDSs meet standards of timeliness, with the target case processing time of 49.5 calendar days or less for DI applicants and 57.9 days or less for SSI applicants. If a DDS has an accuracy rate of less than 90 percent for two consecutive quarters but meets the timeliness standards, SSA has the discretion to decide to provide technical and management assistance (TMA).

If a DDS has an accuracy rate of less than 90 percent and fails to meet one of the timeliness requirements, it is deemed to have "unacceptable performance level" and the SSA must provide TMA. If after 1-2 years performance is still unacceptable, the SSA can take over the administration of DI determinations in that state. Although the SSA has the statutory authority to assume responsibility for conducting disability determinations for a state, it has never exercised this authority. The apparent reason for this is the possible political ramifications to the governors of such a move. Stapleton and Pugh (2001) suggests that exercise of this authority was considered under the Reinvention of Government II initiative, in 1996, and rejected for such reasons. However, it may also be the case that no state has ever deviated by a sufficient amount for a long enough period of time to warrant a takeover. In this case, the threat of takeover may be sufficient to induce state governors to apply subjective admission criteria only up to an existing threshold level. 


\section{Data}

This study links Social Security Administration data from 1982 through 2013 to data on political variables collected by Besley and Case (1995a) and Besley and Case (1995b) for the years until 2000, and collected by ourselves after year $2000^{18}$. We also collected information on case law in various federal districts.

Given the separate data sources we divide the analysis in pre and post year $2000^{19}$. The disability application variables, reported in Panel A of Table 1, include applications and allowance rates for individuals who apply for DI or SSI separately as well as individuals who apply for DI and SSI combined (concurrent). The allowance rate is defined as the number of approved applications at the DDS level divided by the total number of applications. The denominator of this outcome is reported as the number of applications for DI and SSI separately as well as combined DI/SSI applications. Table 1 shows that about 43 percent of DI claims and 40 percent of SSI claims are accepted. Moreover, this number has been increasing over time up until 2000. In 1982 only about 35 percent of DI applications and 20 percent of DI-SSI applications were accepted. These allowance rates rose to a peak of 54 percent of DI applicants and 35 percent of SSI applicants both in 1992 and in 2001 (see Figures 1 and 2).

State demographic and economic variables are reported in Panel B of Table 1. The unemployment rate averaged about 6 percent during this period though in the postliberalization period (after 1984) it was on average only about 5.5 percent. States vary a great deal in their unemployment rate, however. For example, during that time period both West Virginia (in 1985) and Louisiana (1986) had unemployment rates well over 10

Table 1 Summary statistics for disability application and state demographic variables before 2000

\begin{tabular}{|c|c|c|c|c|c|}
\hline & $N$ & Mean & Standard Dev & Min & Max \\
\hline \multicolumn{6}{|l|}{ Panel A: disability application variables } \\
\hline Dl applications & 950 & 11,581 & 12,088 & 540 & 68,524 \\
\hline DI allowance rate & 950 & 0.432 & 0.074 & 0.240 & 0.650 \\
\hline SSI applications & 950 & 15,759 & 20,501 & 214 & 136,419 \\
\hline DI and SSI combined allowance rates & 950 & 0.293 & 0.068 & 0.130 & 0.550 \\
\hline DI total applications (DI + concurrent applications) & 950 & 20,907 & 21,353 & 870 & 139,725 \\
\hline DI total allowance rates (DI + concurrent rates) & 950 & 0.371 & 0.070 & 0.200 & 0.620 \\
\hline \multicolumn{6}{|l|}{ Panel B: state demographic and economic variables } \\
\hline Unemployment rate & 950 & 0.060 & 0.022 & 0.020 & 0.180 \\
\hline Unemployment rate from 1984-2000 & 800 & 0.056 & 0.018 & 0.020 & 0.130 \\
\hline Labor force participation rate & 950 & 0.669 & 0.040 & 0.510 & 0.760 \\
\hline DI replacement rate & 950 & 0.365 & 0.046 & 0.250 & 0.549 \\
\hline UI replacement rate & 950 & 0.370 & 0.053 & 0.200 & 0.530 \\
\hline Real family assistance per capital (\$1982) & 864 & 0.040 & 0.025 & 0.005 & 0.132 \\
\hline Mean personal income $(\times 1000)$ & 950 & 19.496 & 5.744 & 8.990 & 37.547 \\
\hline Fraction of population below poverty line & 950 & 0.138 & 0.042 & 0.030 & 0.280 \\
\hline Fraction of population below $100-125 \%$ of poverty & 950 & 0.048 & 0.014 & 0.010 & 0.090 \\
\hline Fraction of population between $125-150 \%$ of poverty & 950 & 0.050 & 0.014 & 0.010 & 0.100 \\
\hline Percentage with health insurance coverage & 950 & 0.754 & 0.057 & 0.560 & 0.880 \\
\hline Fraction of population that is working age & 950 & 0.613 & 0.023 & 0.530 & 0.680 \\
\hline Fraction of population aged 5-17 & 912 & 0.191 & 0.017 & 0.070 & 0.269 \\
\hline Fraction of population married & 950 & 0.493 & 0.023 & 0.420 & 0.560 \\
\hline Fraction of population that is white & 950 & 0.807 & 0.141 & 0.220 & 1.000 \\
\hline
\end{tabular}




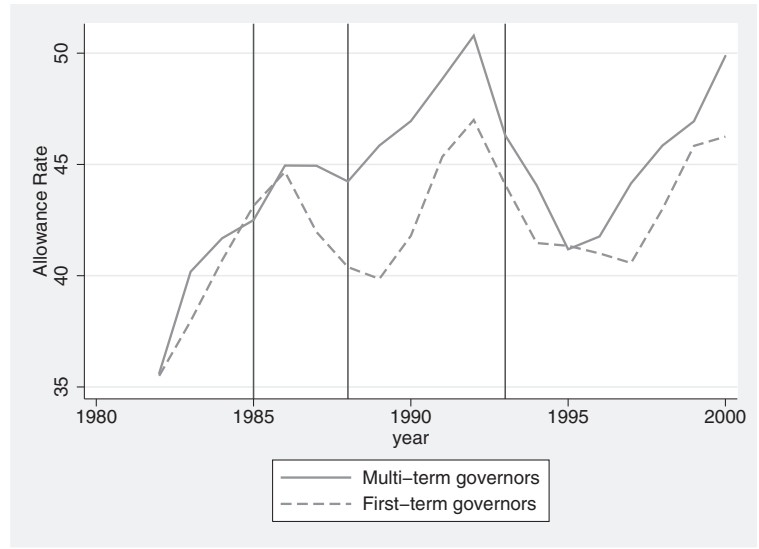

Figure $1 \mathrm{DI}$ allowance rates.

percent. In contrast, in those years New Hampshire and Massachusetts had unemployment rates of well below 5 percent. Similarly, 25 percent of the population lives below 150 percent of poverty. However, this varies widely as in some states less than 10 percent of the population lives below 150 percent of poverty (Connecticut) and in some states over 40 percent of the population lives below poverty (Mississippi). These factors are useful in illustrating the reason why, due to various economic factors, states are likely to differ widely in their allowance rates and the political value of a higher allowance rate.

Another source of variation in the demand for disability insurance is the relative value of DI payments. There is considerable variation in the DI replacement rate (i.e. the average DI payment/the average wage) as well as the unemployment insurance (UI) replacement rate (i.e. the average UI payment/the average wage). There is also variation in the number of people with health insurance (on average 75 percent, but as low as 55 percent.) This is particularly relevant because individuals are eligible for Medicare 24 months after an individual is deemed disabled. These factors regarding access to public welfare may also influence demand and thus the political value of disability insurance.

The political variables are reported in Table 2. Panel A of Table 2 reports descriptive variables about the governors. About 60 percent of the state-years have governors serving

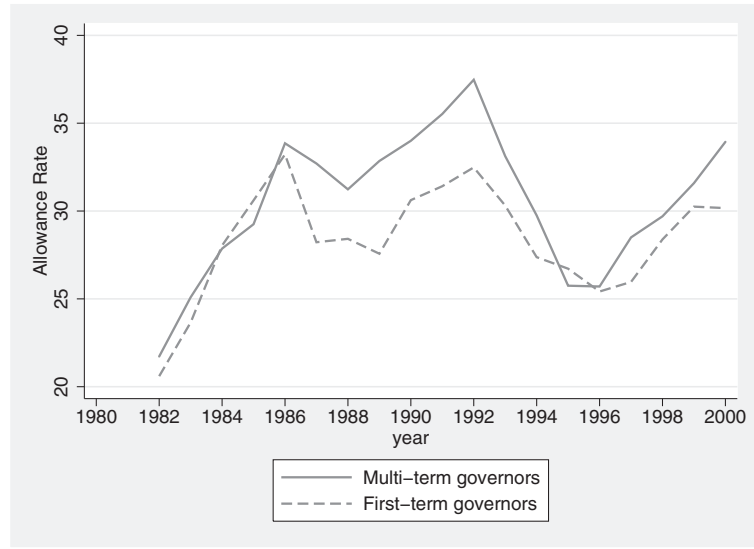

Figure $2 \mathrm{DI}-\mathrm{SSI}$ allowance rates. 
Table 2 Summary statistics for political variables before $\mathbf{2 0 0 0}$

\begin{tabular}{|c|c|c|c|c|c|}
\hline & $N$ & Mean & Std. Dev. & Min & Max \\
\hline \multicolumn{6}{|l|}{ Panel A: gubernatorial descriptive variables } \\
\hline First term governors & 895 & 0.607 & 0.489 & 0.000 & 1.000 \\
\hline Second term governors & 895 & 0.306 & 0.461 & 0.000 & 1.000 \\
\hline Third term or later governors & 895 & 0.087 & 0.282 & 0.000 & 1.000 \\
\hline Governor is a democrat & 912 & 0.487 & 0.500 & 0.000 & 1.000 \\
\hline Governor's age & 912 & 53.50 & 7.90 & 34.00 & 78.00 \\
\hline \multicolumn{6}{|l|}{ Panel B: gubernatorial outcome variables } \\
\hline Incumbents lost re-election & 234 & 0.128 & 0.335 & 0.000 & 1.000 \\
\hline Incumbents could not run for re-election & 905 & 0.239 & 0.427 & 0.000 & 1.000 \\
\hline Incumbents eligible to run but did not & 839 & 0.175 & 0.380 & 0.000 & 1.000 \\
\hline Percent of votes captured by winner & 250 & 56.88 & 7.69 & 35.40 & 82.40 \\
\hline Governors won with a margin of greater than 10 percentage points & 950 & 0.625 & 0.484 & 0.000 & 1.000 \\
\hline \multicolumn{6}{|l|}{ Panel C: rules impacting gubernatorial influence/power } \\
\hline Governors has a line-item veto & 912 & 0.854 & 0.353 & 0.000 & 1.000 \\
\hline Super-majority requirements for tax or expenditure increase & 900 & 0.183 & 0.387 & 0.000 & 1.000 \\
\hline State has a limitation on tax or expenditure increases & 900 & 0.453 & 0.498 & 0.000 & 1.000 \\
\hline State has a restrictive tax/expenditure limitations & 900 & 0.258 & 0.438 & 0.000 & 1.000 \\
\hline \multicolumn{6}{|l|}{ Panel D: other political variables } \\
\hline One party received more than 60 percent of votes & 384 & 0.167 & 0.373 & 0.000 & 1.000 \\
\hline Fraction of state senate members who are democrats & 891 & 0.573 & 0.176 & 0.114 & 1.000 \\
\hline Fraction of state house or assembly members who are democrats & 892 & 0.567 & 0.173 & 0.157 & 0.952 \\
\hline Fraction of state senate members who are women & 912 & 0.191 & 0.085 & 0.016 & 0.433 \\
\hline Fraction of state house or assembly members who are women & 912 & 0.142 & 0.093 & 0.000 & 0.469 \\
\hline Governor and legislative majority are of opposite parties & 912 & 0.475 & 0.500 & 0.000 & 1.000 \\
\hline Governor and the president are of the same party & 950 & 0.382 & 0.486 & 0.000 & 1.000 \\
\hline Governor and the president are of different parties & 950 & 0.618 & 0.486 & 0.000 & 1.000 \\
\hline Governor is a republican and the president is a democrat & 909 & 0.226 & 0.418 & 0.000 & 1.000 \\
\hline Percentage of expenditures that are deficit spending & 864 & 0.438 & 0.080 & 0.238 & 0.705 \\
\hline
\end{tabular}

their first term in office. About 30 percent of the state-years have governors serving their second term in office. About 49 percent of the state-years have democratic governors. The average governor is about 54 years old. In addition to the descriptive variables in Panel A, we also report some outcome variables in Panel B. Only about 13 percent of incumbents lose re-election (either in a primary or a general election). About one-quarter of the sample are ineligible for another term. Another 17 percent were eligible to run, but did not do so. Thus governors who did not get re-elected even though they were eligible for re-election represent about 30 percent of the sample.

Panel $\mathrm{C}$ of Table 2 reports rules which may limit gubernatorial power. Such limitation might influence his/her ability to control state bureaucrats (and thus allowance rates). Over 80 percent of the sample has gubernatorial line-item veto, where the governor can eliminate individual items in omnibus legislation. Only 20 percent of the sample has supermajority requirements to approve tax increases. 45 percent of the sample has indexed limits on tax and expenditure changes but only 25 percent of the sample has limits that are restrictive.

Panel D of Table 2 reports other political variables relevant for gubernatorial political power. In 16 percent of the sample, one party received more than 60 percent of the vote 
indicating strong party ties. On average, 57 percent of state senate members and 56 percent of state house members are democrats and indeed about 56 percent of the sample has a democratic legislature. In general, democrats are believed to be associated with higher government spending and in general fiscal laxness. However, we find evidence of a significantly negative relationship between having a democratic legislature and the fraction of expenditures that are deficit funded. About 20 percent of the state senate members and 14 percent of state assembly members are women and again, there appears to be little correlation with government expenditures. Higher fractions of women in political office are sometimes thought to indicate the political liberalness of an area and would be associated with higher spending levels. We find evidence that a higher fraction of women is associated (in a marginally significant sense) to higher rates of deficit spending. Finally, about 48 percent of the sample has a split government, where the governor and the majority of the legislature are of opposite parties.

Panel D also reports the relationship between the governor's party and the current president's party. The relationship between the governor and president's party may relate to career concerns of governors. Nearly 40 percent of the sample has governors who are of the same party as the president. Of the 60 percent of the sample in which the governors and presidents are of opposite parties, about 23 percent have republican governors and democratic presidents. The political party may be important if there are different reputational and electoral consequences for higher welfare spending by political party.

\section{Describing gubernatorial behavior}

Gubernatorial behavior may be a relevant factor in disability determinations and thus legal changes which allow greater scope for governor's to exercise discretion may be important in explaining differences in outcomes. Previous work has extensively documented the trends in DI and the role that this has played in US unemployment rates (Autor and Duggan 2003). Using similar data, it is clear that increases in both acceptance rates and application rates contributed to the expansion of the disability program. Figures 1 and 3 illustrate the DI allowance rates and application rates (per 1000 inhabitants) (respectively) from 1982 until 2000. Figures 2 and 4 show the corresponding trends for SSI-DI. These figures show the rates of first-term governors and single term governors in the solid and dashed lines respectively. Between 1982 and 1990 application rates are largely flat in both single term and multi-term governors and if anything, slightly (though not significantly) higher among first-term governors. Despite this relatively constant application rate, allowance rates increased steadily from 1982-1986 among both single term and multi-term governors. The divergence between single and multi-term governors' allowance rates begin in 1986 and continue through 1996. Although allowance rates decline in states with multi-term governors between 1986 and 1988, these rates remain constant among multi-term governors. After 1998, both groups dramatically increase allowance rates, though somewhat more rapidly among multi-term governors, until 1992 and then rapidly reduce allowance rates until 1996. Application rates, on the other hand, appear to largely co-move for both single term and multi-term governors, increasing steadily through 1994 and then decreasing after 1994. After 1996, disability insurance allowance rates once again rise, while application rates continue to fall. Overall the divergence between first and multi-term governors seems to grow when allowance rates increase, and shrink when allowance rates decrease. 


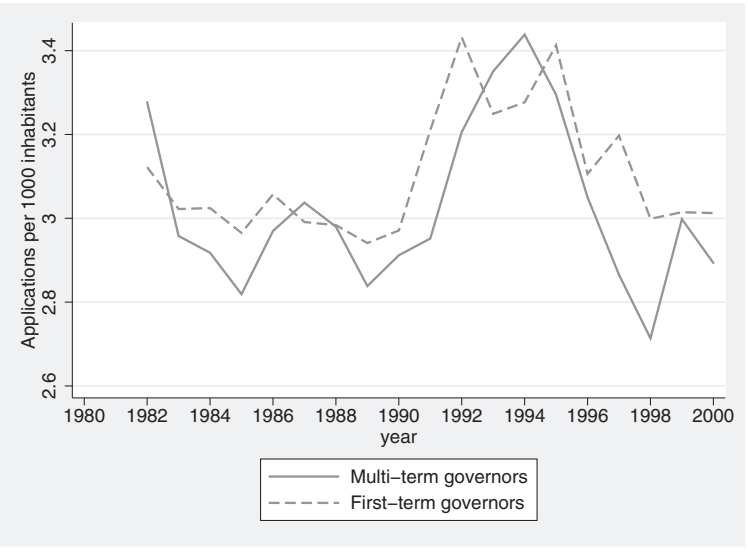

Figure 3 DI applications (per 1000 inhabitants).

Figure 5 shows that after 2001, in a period of consistent fall in allowance rates the difference between first and multi-term governors seems to have vanished. The timing correspondence between allowance rates and legal ruling and lack of correspondence between applications and allowance rates raises two potential factors that may affect the adjustment of DI allowance rates by governors. The first is flexibility. Even if a governor wishes to adjust allowance rates for political purposes, he or she cannot do so if there are clearly objective standards for application acceptance. Increasing allowance rates are a clear signal that such standards are being relaxed.

The introduction of increased flexibility after 1986 increased the potential for governors to increase the allowance rates for political reasons. However, a likely second factor is that probability of detection. If SSA monitoring was perfect, then such deviations in allowance rates would be detected with a high probability. If there are political consequences for such detection (e.g. reputational consequences) governors will not tend to deviate from the targeted allowance rate. Put another way, for a fixed penalty from the SSA, an increased probability of detection should reduce the willingness of governors to deviate from the targeted allowance rate. To test this we compare states in which the federal circuit acquiesced to the SSA rulings (and saw less review and appeal and we refer to

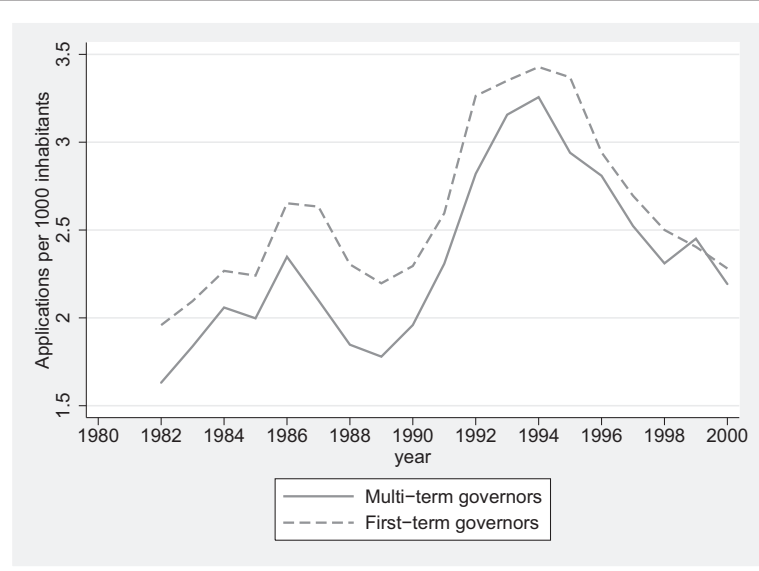

Figure 4 DI-SSI applications (per 1000 inhabitants). 

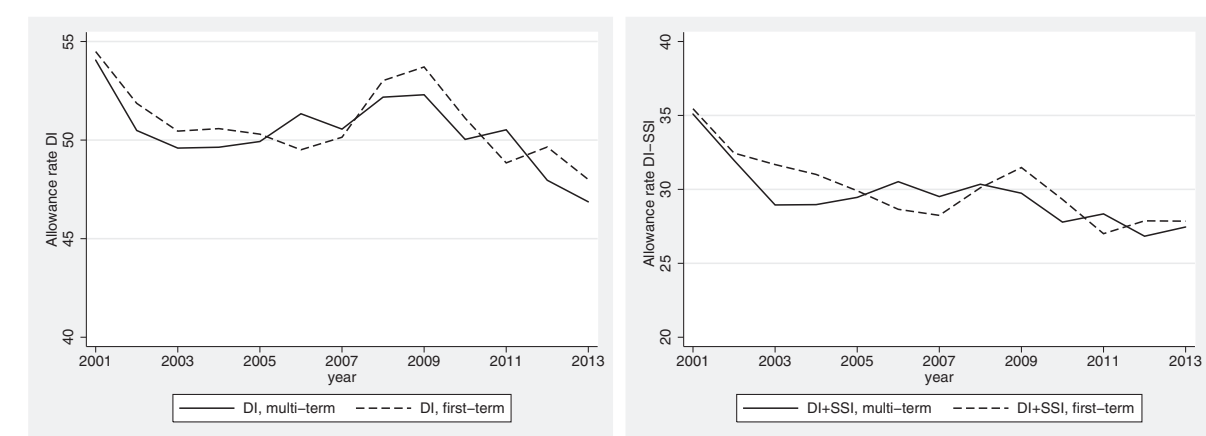

Figure 5 Differences in Disability Insurance (Left) and DI SSI Concurrent (Right) allowance rates between first and multi-term governors between 2001 and 2013.

as "low monitored") to states which did not acquiesce (and saw greater review and thus we refer to as "strictly monitored"). We find evidence consistent with this theory. The right graph in Figure 6 shows allowance rates in strictly monitored states.

There is little divergence between single term and multi-term governors (except in 1990) and frequent crossing of the two lines. In contrast, the left graph shows allowance rates for low monitored states. In these states, while first-term governors appear to increase and decrease their allowance rates, multi-term governors appear to either hold steady or increase allowance rates.

A question that then must be answered is why single term governors do not adjust to lax monitoring in the same way as multi-term governors-i.e. why do single term governors appear to reduce allowance rates even when monitoring is relatively low. A key issue may be the information governors have about the targeted rate from the SSA and what allowance rate level constitutes a small versus a large deviation from the targeted rate. Second term and later governors have much more information having had signals from the SSA about the likelihood of detection and therefore adjust DI rates much more as economic/political needs arise. First-term governors may be wary of moving DI allowance rates in because they do not have enough information about how the Social Security Administration will react. Thus we see much more movement and

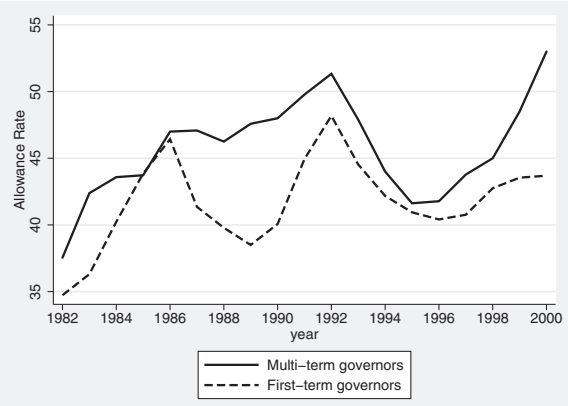

Low Monitored

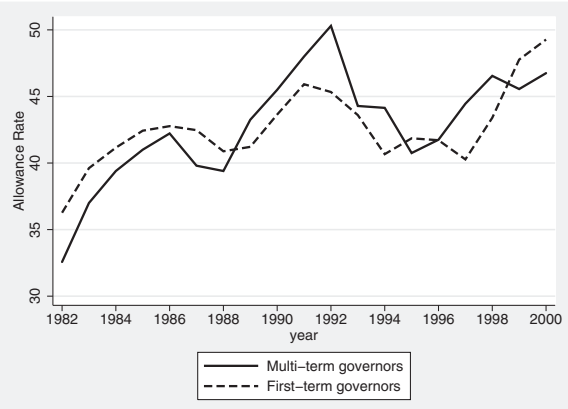

Highly Monitored

Figure 6 Differences in disability insurance allowance rates between first and multi-term governors in acquiescing (low monitored, left) and non-acquiescing (highly monitored, right) federal circuit courts. 
larger differences by governor term length during periods of little scrutiny and reduced monitoring.

\subsection{Summary of the model results}

We formally illustrate the role that governor term length, in the Online Appendix A. We develop a simple model of strategic behavior between a governor and the SSA in the context of different legal regimes for disability determinations.

Results from the strategic model suggest that for a given governor, acceptance rates in the second period should be at least as large as in the first period. This comes simply from the relatively simplistic monitoring and penalty tools used by the SSA in which warnings indicate significant deviations, and thus allow governors to impose minor adjustments and avoid any additional penalty.

First-term governors, however, will not have the benefit of this warning and thus must start from scratch, setting allowance rates with no information on the SSA's targeted allowance rate level. Note also that this model illustrates that the utility from deviation is going to be a key in determining the extent of deviation a governor may wish to impose in either the first or second period, conditional on a given expected penalty level. However, as the penalty level adjusts, for a given utility level, governors will seek to minimize the distance between the allowance rate they set in the first period and the perceived SSA targeted allowance rate. Thus we have three main predictions:

1. For a given governor, allowance rates should be weakly increasing over time as the risk of detection are fixed and the returns to doing so are at least increasing.

2. For a given penalty level, governors should set higher allowance rates if the returns to doing so are higher. This is based on a simple cost-benefit trade-off; as the returns to increased allowance rates increases, governors will optimize conditional on the penalty level and the more information a governor has about the targeted allowance rate of the SSA (and thus the degree to which they risk detection for deviating), the greater is the increased allowance rate.

3. For a given utility level, governors should set lower allowance rates as the probability of detection increase. This tendency will be reduced the more information a governor has about the target allowance rate of the SSA (and thus for multi-term governors).

Prediction 3 hinges on the idea that the greater the uncertainty, the more governors must worry that their targeted increase will trigger a penalty and warning. With perfect information the governor can set the maximum allowance rates at the target rate plus the cost of take-over. Thus, the more information a governor has about the SSA targeted rate, the less uncertainty around the maximum increased allowance rate a governor may impose without incurring the penalty. This will thus increase deviations when the returns are higher (because the expected costs are lower) but also reduce the effects of changes in the probability of detection because the space over which that detection may occur is smaller. While in our model we don't take into account that disability applicants might have an incentive to apply for benefits in the second period, we are going to test empirically for the existence of such responses. We are also going to test alternative relationships between political and electoral variables and allowance rates which allows 
us to explore the extent to which particular characteristics which affect the returns to increasing allowances and the costs if detected.

\section{Results on changes in disability insurance allowance rates}

To test this model and determine how realistic and substantial such behavior appears to be, we test the three predictions sequentially. To do this, we consider the effect on allowance rates and then verify that there does not appear to be significant changes in application rates. Table 3 shows the average allowance rates and applications by the term number. Allowance rates, for Disability Insurance only, and for concurrent Disability Insurance and Supplementary Security Insurance, tend to be increasing in the term number, while applications tend to decrease. From this simple table it doesn't seem that applicants act strategically, applying more often when governors are in their later terms. The other thing to notice that the large majority of governors are in their first or second term.

Changes in the policy, training, and other factors which may influence determination procedures are typically established by the director of DDS, a political appointee ${ }^{20}$. Since governors are somewhat constrained in changing the appointment during the term, we would expect this learning effect to be stifled in the first term and more prominent in later terms. Since very few governors are beyond their second term we include separate effects for first-term years and later term years in office. Indeed it appears that most of the effect is concentrated in the later years in office. This result is especially indicative because there is state level variation in the number of years in a given term. Thus governors who have been in office for anywhere ranging from 2 to 6 years will be "multi-term" governors if their state has shorter term-lengths.

We move to a multivariate analysis beginning with a parsimonious specification that regresses allowance rates on a dummy which is 1 for multi-term governor, with state and year fixed effects ${ }^{21}$.

$$
\left(\frac{\# \text { of Allowed }}{\# \text { of Applications }}\right)_{s t}=\beta_{0}+\beta_{1}(\text { multiterm })_{s t}+\delta_{s}+\delta_{t}+\varepsilon_{s t}
$$

Equation 1 shows the basic estimating equation of Allowance Rates on an indicator for multi-term governors, state and time fixed effects, where $s$ denotes state and $t$ denotes year, and goes from 1982 to 2000. Later we use more recent data to analyze the 2001-2013 period.

The results of this regression are reported in column (1) of Table 4. An additional term in office increases allowance rates by about 1.31 percent or about three percent. What else might explain the difference in allowance rates between first and subsequent terms? The status of the economy (unemployment rates, poverty, incomes) might influence application rates, and allowance rates, as well as re-election probabilities ${ }^{22}$. Booming economies

Table 3 Average allowance rates and applications by term number before 2000

\begin{tabular}{|c|c|c|c|c|c|}
\hline \multirow{2}{*}{$\begin{array}{l}\text { Term } \\
\text { Number }\end{array}$} & \multicolumn{2}{|c|}{ Allowance rates } & \multicolumn{2}{|c|}{ Applications } & \multirow[t]{2}{*}{ Obs. } \\
\hline & DI & $\mathrm{DI}+\mathrm{SSI}$ & DI & $\mathrm{DI}+\mathrm{SSI}$ & \\
\hline 1 & 0.42 & 0.28 & 11,902 & 9,927 & 543 \\
\hline 2 & 0.44 & 0.30 & 12,603 & 9,756 & 274 \\
\hline 3 or more & 0.46 & 0.31 & 10,006 & 6,869 & 78 \\
\hline
\end{tabular}


Table 4 Estimates of differences in allowance rates by gubernatorial term length before 2000

\begin{tabular}{|c|c|c|c|c|c|c|c|c|c|c|c|c|}
\hline \multirow[b]{2}{*}{ Dependent variable } & (1) & $(2)$ & (3) & (4) & (5) & (6) & (7) & (8) & (9) & $(10)$ & (11) & (12) \\
\hline & \multicolumn{3}{|c|}{$\begin{array}{l}\text { Disability Insurance (DI) } \\
\text { allowance rate (in \%) }\end{array}$} & \multicolumn{3}{|c|}{$\begin{array}{l}\text { Concurrent (DI + SSI) } \\
\text { allowance rate (in \%) }\end{array}$} & \multicolumn{3}{|c|}{$\begin{array}{l}\text { Disability Insurance (DI) } \\
\text { log-applications (in \%) }\end{array}$} & \multicolumn{3}{|c|}{$\begin{array}{c}\text { Concurrent (DI + SSI) } \\
\text { log-applications (in \%) }\end{array}$} \\
\hline \multirow{3}{*}{$\begin{array}{l}\text { Mean } \\
=1 \text { if multi-term governor }\end{array}$} & & 43.90 & & & 30.08 & & & 892.8 & & & 870.8 & \\
\hline & $1.31^{* *}$ & $1.35^{* *}$ & $0.91^{* *}$ & $1.67^{* * *}$ & $1.61^{* *}$ & $1.24^{* * *}$ & $-2.36^{*}$ & -0.56 & 0.48 & -2.21 & -1.15 & -1.48 \\
\hline & $(0.51)$ & $(0.62)$ & $(0.43)$ & $(0.57)$ & $(0.65)$ & $(0.45)$ & $(1.38)$ & (1.33) & (1.59) & $(1.70)$ & (1.65) & (2.40) \\
\hline \multirow{2}{*}{$\begin{array}{l}=1 \text { if governor cannot } \\
\text { run again }\end{array}$} & $-1.28^{* *}$ & -1.01 & $-0.83^{*}$ & $-1.88^{* * *}$ & $-1.67^{* * *}$ & $-0.86^{*}$ & $3.46^{* *}$ & 1.79 & 0.07 & $3.88^{* *}$ & $3.16^{*}$ & 0.20 \\
\hline & $(0.63)$ & $(0.63)$ & $(0.47)$ & $(0.63)$ & $(0.61)$ & $(0.45)$ & $(1.66)$ & (1.49) & (1.88) & $(1.87)$ & (1.68) & (2.62) \\
\hline \multirow{2}{*}{$\begin{array}{l}=1 \text { if the previous governor } \\
\text { is from the same party }\end{array}$} & & 0.84 & 0.48 & & 0.21 & 0.62 & & -0.02 & 2.18 & & -0.26 & -3.43 \\
\hline & & $(0.54)$ & $(0.43)$ & & $(0.53)$ & $(0.44)$ & & $(1.22)$ & $(1.84)$ & & $(1.67)$ & (2.44) \\
\hline \multirow[t]{2}{*}{ Election year } & & 0.15 & 0.06 & & -0.12 & $0.48^{* *}$ & & -0.86 & $-1.06^{*}$ & & 0.05 & 0.88 \\
\hline & & $(0.31)$ & (0.18) & & $(0.31)$ & (0.19) & & $(0.71)$ & $(0.59)$ & & $(0.84)$ & $(0.80)$ \\
\hline \multirow[t]{2}{*}{ Employed/Population } & & $32.56^{* *}$ & $21.04^{* *}$ & & -1.19 & 3.64 & & $-261.26^{* * *}$ & $-278.19^{* * *}$ & & $-226.33^{* * *}$ & $-349.03^{* * *}$ \\
\hline & & $(16.09)$ & $(8.35)$ & & $(17.59)$ & $(7.81)$ & & $(31.42)$ & (33.76) & & $(44.35)$ & $(50.08)$ \\
\hline \multirow[t]{2}{*}{ Mean personal income } & & -0.05 & $-0.15^{* *}$ & & -0.01 & $-0.25^{* * *}$ & & 0.26 & $1.31^{* * *}$ & & -0.44 & -0.01 \\
\hline & & $(0.19)$ & $(0.07)$ & & $(0.17)$ & $(0.07)$ & & $(0.51)$ & $(0.31)$ & & $(0.54)$ & $(0.43)$ \\
\hline \multirow[t]{2}{*}{$\%$ of pop below $100 \%$ of poverty level } & & 0.72 & -7.85 & & -7.38 & $-19.16^{* * *}$ & & 15.95 & 28.17 & & 1.12 & 25.41 \\
\hline & & $(11.83)$ & (6.43) & & $(10.40)$ & (6.35) & & $(22.26)$ & $(24.36)$ & & $(27.85)$ & $(31.37)$ \\
\hline \multirow[t]{2}{*}{$\%$ of working age pop $(18 \leq$ age $\leq 64)$} & & -25.99 & $33.05^{* *}$ & & 2.74 & $60.77^{* * *}$ & & -32.93 & $237.86^{* * *}$ & & 47.30 & $120.31^{*}$ \\
\hline & & $(23.00)$ & (13.12) & & $(21.90)$ & $(13.31)$ & & $(45.63)$ & $(46.76)$ & & $(51.65)$ & $(64.38)$ \\
\hline \multirow[t]{2}{*}{ Married } & & -8.48 & $-31.88^{* * *}$ & & -27.65 & $-42.76^{* * *}$ & & $104.62^{* * *}$ & -19.24 & & -28.11 & 17.71 \\
\hline & & $(19.29)$ & $(11.75)$ & & $(18.75)$ & $(12.07)$ & & (39.94) & $(44.30)$ & & $(48.96)$ & (58.78) \\
\hline \multirow[t]{2}{*}{ White } & & 1.14 & $10.35^{* * *}$ & & 6.42 & 3.32 & & -23.60 & $-239.73^{* * *}$ & & -4.40 & $-273.05^{* * *}$ \\
\hline & & $(10.22)$ & (3.23) & & (9.86) & (2.55) & & $(23.83)$ & $(16.92)$ & & $(25.81)$ & $(24.31)$ \\
\hline \multirow[t]{2}{*}{ Age-adjusted-rate } & & -0.00 & $-0.04^{* * *}$ & & 0.01 & $-0.02^{* * *}$ & & 0.01 & $0.10^{* * *}$ & & $0.09^{* *}$ & 0.00 \\
\hline & & $(0.01)$ & $(0.00)$ & & $(0.01)$ & $(0.00)$ & & $(0.02)$ & $(0.02)$ & & $(0.04)$ & $(0.03)$ \\
\hline
\end{tabular}


Table 4 Estimates of differences in allowance rates by gubernatorial term length before $\mathbf{2 0 0 0}$ (Continued)

\begin{tabular}{|c|c|c|c|c|c|c|c|c|c|c|c|c|}
\hline \multirow[t]{2}{*}{ DI replacement rate } & & -2.38 & 0.77 & & 10.71 & -2.05 & & $-110.02^{* * *}$ & $-72.10^{* * *}$ & & $-203.69^{* * *}$ & $-267.26^{* * *}$ \\
\hline & & $(12.63)$ & $(5.90)$ & & $(12.25)$ & $(6.24)$ & & (31.39) & $(25.18)$ & & $(43.19)$ & $(33.56)$ \\
\hline \multirow[t]{2}{*}{ UI replacement rate } & & 1.40 & -7.66 & & 10.87 & 5.48 & & 28.12 & -0.92 & & 39.02 & -37.99 \\
\hline & & $(6.26)$ & $(5.24)$ & & $(7.99)$ & $(5.36)$ & & $(18.51)$ & $(23.17)$ & & $(28.70)$ & $(30.26)$ \\
\hline State FE & Y & Y & Y & Y & Y & Y & Y & Y & Y & Y & Y & Y \\
\hline Year FE & Y & Y & Y & Y & Y & Y & Y & Y & Y & Y & Y & Y \\
\hline Clustered standard errors & Y & Y & $\mathrm{N}$ & Y & Y & $\mathrm{N}$ & Y & Y & N & Y & Y & N \\
\hline Estimation method & OLS & OLS & GLS & OLS & OLS & GLS & OLS & OLS & GLS & OLS & OLS & GLS \\
\hline Observations & 749 & 708 & 708 & 749 & 708 & 708 & 749 & 708 & 708 & 749 & 708 & 708 \\
\hline R-squared & 0.791 & 0.795 & - & 0.729 & 0.730 & - & 0.993 & 0.994 & & 0.991 & 0.992 & - \\
\hline
\end{tabular}

Heteroskedasticity and autocorrelation (4 lags) robust standard errors at the state level in parentheses. Coefficients that are significant at the .10 [.05] (.01) are marked with *[**]***). Regressions all include additional controls for state marriage rates and age-adjusted state death rates. 
might lead to a re-election and to a pool of more strictly disabled applicants. Recessions might also alter the standards required by DDS decision makers.

But the estimate appears to be robust to the inclusion of a range of state-time varying covariates including labor force participation, average income, poverty rate and demographic controls (results reported in column 2). It is also robust to the inclusion of an election year dummy, showing that electoral cycles are not driving the results. It also does not appear very sensitive to estimation type or corrections for serial correlation. Column (3) reports a specification using a two-step feasible GLS estimator and assuming an $\mathrm{AR}(1)$ process for the error terms. The coefficient is more precisely estimated but not significantly different than the OLS estimates.

Before discussing whether applications vary by term number (Columns 7 to 12), the observed differences in allowance rates could be related to political survival and political savviness. Given the strong prediction of the model that learning implies a given governor should increase allowance rates, we estimate a specification with governor and year fixed effects (note that state fixed effects will be subsumed in the specification). In these specification, single term governors who are never re-elected are absorbed by the governor fixed effects. Thus, identification for the first-term effect comes from comparing governors in their first-term to later-terms, essentially treating multi-term governors as panel observations on the same individual. This specification is shown in Equation 2 where the equation is estimated for governor $g$ in state $s$ in year $t$.

$$
\left.\left(\frac{\# \text { of Allowed }}{\# \text { of Applications }}\right)_{g s t}\right)=\beta_{0}+\beta_{1}(\text { multiterm })_{g s t}+\delta_{g}+\delta_{t}+\varepsilon_{g s t}
$$

Table 5 reports a comparison of estimates using governor fixed effects to those using state fixed effects. The DI only allowance rate is still lower for first-term governors relative to second term governors. Moreover, if a governor cannot run again (he or she is prevented by term limit laws), the effect is also smaller in the governor fixed effects setting, providing additional evidence of career concerns. Indeed it appears that multi-term governors increase the allowance rates by almost 1.47 percentage points. This specification also suggests that this may not be purely due to governor electoral survival. It does not appear that there are high and low allowance rate governors and that high allowance governors simply have longer term lengths. Rather, it appears that for a given governor, as they are in office longer, they relax the standards for admission into disability insurance. To further support this, we restrict the sample to governors in their first term only, adding a dummy equal to one for governors who are going to be re-elected. From the results reported in columns (3) and (6), the results do not seem to be driven by selection. If anything governors who are going to be re-elected have lower allowance rates. Since all the specification control for electoral cycles the results appear more consistent with a model of learning over time. Additionally note that allowance rates are greater if the previous governor was of the same party. While the significance of this coefficient is sensitive to specification, it is consistent with a story of gubernatorial learning about the SSA targeting and monitoring strategy. If it is the case that governors of the same party are more likely to share information and staff than governors of different party, then we would expect some persistence in the learning if a new governor succeeds someone from his or her own party. 


\begin{tabular}{|c|c|c|c|c|c|c|}
\hline \multirow[b]{2}{*}{ Dependent variable } & (1) & (2) & (3) & (4) & (5) & (6) \\
\hline & \multicolumn{3}{|c|}{$\begin{array}{l}\text { Disability Insurance (DI) } \\
\text { allowance rate (in \%) }\end{array}$} & \multicolumn{3}{|c|}{$\begin{array}{l}\text { Concurrent (DI + SSI) } \\
\text { allowance rate (in \%) }\end{array}$} \\
\hline Mean & & 44.02 & & & 30.15 & \\
\hline \multirow[t]{2}{*}{$=1$ if multi-term governor } & $1.35^{* *}$ & $1.47^{*}$ & & $1.61^{* *}$ & $1.60^{*}$ & \\
\hline & $(0.62)$ & $(0.80)$ & & $(0.65)$ & $(0.84)$ & \\
\hline \multirow{2}{*}{$\begin{array}{l}=1 \text { if governor will serve } \\
\text { more than one term }\end{array}$} & & & -0.56 & & & -1.19 \\
\hline & & & $(0.67)$ & & & $(0.75)$ \\
\hline \multirow{2}{*}{$\begin{array}{l}=1 \text { if previous governor is } \\
\text { from the same party }\end{array}$} & 0.84 & $1.68^{* *}$ & $1.40^{* *}$ & 0.21 & 0.36 & 0.85 \\
\hline & $(0.56)$ & $(0.81)$ & $(0.64)$ & $(0.53)$ & $(0.79)$ & $(0.61)$ \\
\hline \multirow{2}{*}{$\begin{array}{l}=1 \text { if governor cannot } \\
\text { run again }\end{array}$} & -1.01 & $-1.52^{* *}$ & $-2.19 * *$ & $-1.67^{* * *}$ & $-1.75^{* *}$ & $-2.51^{* * *}$ \\
\hline & $(0.63)$ & $(0.76)$ & $(1.00)$ & $(0.62)$ & $(0.80)$ & $(0.86)$ \\
\hline \multirow[t]{2}{*}{ Election year } & 0.15 & 0.15 & -0.05 & -0.12 & -0.05 & -0.14 \\
\hline & $(0.34)$ & $(0.38)$ & $(0.40)$ & $(0.35)$ & $(0.38)$ & $(0.43)$ \\
\hline State FE & Y & $\mathrm{N}$ & Y & Y & $\mathrm{N}$ & Y \\
\hline Year FE & Y & Y & Y & Y & Y & Y \\
\hline Governor FE & N & Y & $\mathrm{N}$ & N & Y & $\mathrm{N}$ \\
\hline Observations & 745 & 745 & 457 & 745 & 745 & 457 \\
\hline R-squared & 0.795 & 0.878 & 0.842 & 0.730 & 0.842 & 0.775 \\
\hline
\end{tabular}

With governor fixed effect the standard errors (in parentheses) are clustered at the governor level, with state fixed effects the standard errors are robust to heteroskedasticity and autocorrelation ( 4 lags). Coefficients that are significant at the .10 $[.05](.01)$ are marked with ${ }^{*}\left[{ }^{* *}\right]^{(* * *)}$. Regressions all include additional controls for year fixed effects, state marriage rates and age-adjusted state death rates.

A natural concern is that this difference in allowance rates over a governor's tenure reflects a change in the underlying application base. The governor fixed effects specification in part suggests this is not the case since for any given governor term length, there are a range of states and years in which any given governor may be single or multiple term governor. However, if the underlying applicant base is changing with the gubernatorial electoral cycle, this will pose a problem for our identification. To explicitly test this, we estimate a state fixed effect model using applications per 1000 people (in a state-year) ${ }^{23}$.

$$
(\# \text { of Applications })_{g s t}=\beta_{0}+\beta_{1}(\text { multiterm })_{g s t}+\delta_{s}+\delta_{t}+\varepsilon_{g s t}
$$

The results are shown in columns 7 to 12 of Table 4. We find no significant effect and the magnitudes of the coefficients are extremely small. Given that there does not appear to be change in the application rates across term lengths or in later term, there is less concern that allowance rates (which is allowances divided by applications) could be changing due to changes in the number of applicants. A remaining concern is that while the number of applicants is not changing the type of applicant is. While there is little scope to learn on their own experience (after all applicants apply only a few times), information might spread through other means.

In order to test whether the application pool is changing we collected data from the 2000-2007 DI statistical supplements on the distribution of diagnostic types. In Table 6 we regress the differences over time in the Log-Number of DI beneficiaries for each diag- 
Table 6 Estimates of differences in the log-number of DI beneficiaries by diagnostic type and by gubernatorial term length

\begin{tabular}{|c|c|c|c|c|}
\hline \multirow{2}{*}{$\begin{array}{l}\text { Dep. variable } \\
\text { Change in beneficiaries }\end{array}$} & Multiterm & SE & Multiterm & SE \\
\hline & \multicolumn{2}{|c|}{ State FE } & \multicolumn{2}{|c|}{ Governor FE } \\
\hline Congenital & $0.01 *$ & $(0.01)$ & -0.00 & $(0.01)$ \\
\hline Endocrinous & 0.01 & $(0.02)$ & -0.00 & $(0.02)$ \\
\hline Infectious & 0.02 & $(0.02)$ & 0.01 & $(0.02)$ \\
\hline Injuries & 0.02 & $(0.02)$ & 0.03 & $(0.03)$ \\
\hline Total mental & -0.03 & $(0.06)$ & -0.06 & $(0.08)$ \\
\hline Retardation & -0.01 & $(0.02)$ & -0.05 & $(0.03)$ \\
\hline Other mental & -0.02 & $(0.05)$ & -0.01 & $(0.08)$ \\
\hline Neoplasm & 0.00 & $(0.02)$ & -0.01 & $(0.03)$ \\
\hline Blood & -0.01 & $(0.01)$ & -0.02 & $(0.01)$ \\
\hline Circulatory system & -0.00 & $(0.02)$ & 0.01 & $(0.03)$ \\
\hline Digestive system & 0.01 & $(0.01)$ & 0.01 & $(0.02)$ \\
\hline Genitourinary & 0.02 & $(0.01)$ & 0.01 & $(0.02)$ \\
\hline Musculoskeletal & -0.07 & $(0.04)$ & -0.04 & $(0.06)$ \\
\hline Nervous & 0.02 & $(0.02)$ & 0.00 & $(0.03)$ \\
\hline Respiratory & 0.00 & $(0.02)$ & $-0.05^{* *}$ & $(0.02)$ \\
\hline Skin & -0.01 & $(0.01)$ & -0.01 & $(0.01)$ \\
\hline Other mental & 0.01 & $(0.01)$ & -0.00 & $(0.01)$ \\
\hline
\end{tabular}

Based on the DI statistical supplements from 2000 to 2007. Heteroskedasticity and autocorrelation (4 lags) robust standard errors at the state level in parentheses. Coefficients that are significant at the $.10[.05](.01)$ are marked with $\left.{ }^{*}{ }^{* *}\right]\left({ }^{* * *}\right)$. All regressions include year fixed effects, and either state or governor fixed effects.

nostic type $d$, on the multi-term dummy variable, controlling for year and either state or governor fixed effects $(s / g)$. Each coefficient $\beta^{d}$ refers to a different regression ${ }^{24}$ :

$$
\Delta \log (\# \text { of Beneficiaries })_{g s t}^{d}=\beta_{0}^{d}+\beta_{1}^{d}(\text { multiterm })_{g s t}+\delta_{s / g}+\delta_{t}+\varepsilon_{g s t} .
$$

Less that 5 percent of the diagnostic types show significant differences between first and multi-term governors. This finding also suggest that applicants are probably unaware of the differences in allowance rates across terms. Otherwise, marginal applicants, who often report musculoskeletal or back-pain problems, would have an incentive to apply when allowance rates are higher.

The next prediction of the model is that for a given penalty level, the governor will increase allowance rates if the return to doing so is higher. Conditional on a given penalty level, governors may be willing to risk detection if they are more constrained in votebuying tools. To test this we consider state laws which reduce the fiscal freedom of governors. There are two such laws which we consider: first, some states have laws in which there is a tax and expenditure limitation. Twenty-five states have a law of this sort at some point with 6 states changing the law during the 18 year sample span. Second, some states have laws in which a supermajority of the legislature is required to approve any funding increase. This again limits the ability of the governor to expand state-funded programs for political returns. During the sample period, 13 states have such laws and 6 changed their laws. A separate potential restriction on the ability to pass state-funded bills may be if the government is split, i.e. the party of the governor is different from the party of the legislative majority. By the same logic, while there are gains from using DI, if it indeed 
serves as a vote-buying mechanism, it is also risky. Because the costs are unknown, governors who are not constrained from otherwise addressing economic conditions may prefer not to use expand DI maximally while governors who are constrained either through political institutions or economic factors may be forced to increase allowance rates. While a good deal of the political economy literature focuses on unemployment and political outcomes, it is equally plausible that governors who are constrained from social welfare spending through political institutions may use DI as a means to improve the well-being of individuals in their state.

To further explore the relationship between necessity and allowance rates, we estimate regressions with state and year fixed effects within various sub-samples. The results, reported in Table 7, highlight how as governors are constrained, either through economic conditions or political institutions, they are more likely to use DI as a means of public welfare. Column (1) of Table 7 provides estimates for the full sample. In states with high unemployment rates (i.e. higher than the national median) multi-term governors have an even higher allowance rate. This fits with the theory that governors may be using DI as free (from a state budget perspective) way of dealing with adverse economic shocks. The same is not true for high deficit spending states. First-term governors in states which finance a higher percentage of their expenditures through deficits have almost the same acceptance rate as the full sample.

In states with restrictions on tax and expenditure increases, and especially in states with supermajority requirements for new tax or expenditure laws, multi-term governors have much larger acceptance rates relative to first-term governors than in the sample as a whole. This is suggestive of a more "risky" use of DI at times when governors may be constrained from passing other legislation. If higher acceptance rates increase the chance of SSA takeover, then the amount governors increase the acceptance rates by in their second term will be influenced by their ability to pass other interventions (obviating the need for a large increase in DI acceptances) ${ }^{25}$.

Note that republican governors show an even larger multi-term effect than the average multi-term governor. This may be related to two factors. First, republican governors may be in states in which there is a greater distaste for state spending and tax increases. This means that the governor has few options if he or she wishes to expand social protection. Second, republican governors career concerns may be such that higher state deficits are more detrimental than greater usage of federal programs. As a result, republican governors appear to be quite willing to use federal public welfare programs.

In an additional exercise we analyze the four distinct periods of rules, 1982-1985, 1986-1992, and 1993-2000, separately. Table 8 shows that the largest multi-term changes in acceptance rates are between 1993 and 2000 for DI and between 1987 and 2000 for concurrent (DI and SSI). This is in line with the 1986 introduction in court ruling of evidence from treating physicians (rather than SSA physicians). The divergence continued to grow until 1993 when evidentiary standards on pain were tightened and closed almost entirely by the end of the 1990s when the SSA issued a set of unifying evaluation criteria.

Do these results hold in more recent years, when allowance rates started falling steadily over time? In line with Figure 5 the simple answer is no. Controlling for state or governor fixed effects as well as year fixed effects does not resuscitate the difference in allowance 
Table 7 Estimates of differences in allowance rates by gubernatorial term length for subgroups before 2000

(1)

(2)
(3)

(5)

(6)

(7)

(8)

Sample restricted to states in years in which they have

\begin{tabular}{ccccccc}
\hline Full sample & $\begin{array}{c}\text { Unemployment } \\
\text { rate above } \\
\text { national median }\end{array}$ & $\begin{array}{c}\text { \% of expenditures } \\
\text { which are deficit } \\
\text { spending above }\end{array}$ & $\begin{array}{c}\text { Split government } \\
\text { (governor and } \\
\text { legislative }\end{array}$ & $\begin{array}{c}\text { Restrictions } \\
\text { on tax and } \\
\text { expenditure }\end{array}$ & $\begin{array}{c}\text { Super-majority } \\
\text { requirements for } \\
\text { new tax or }\end{array}$ & $\begin{array}{c}\text { Republican } \\
\text { governor }\end{array}$ \\
\hline
\end{tabular}

national median spending above legislative

governo

Governor with

line-item veto

(Can reject

single items

deficit spending opposite parties)

\begin{tabular}{|c|c|c|c|c|c|c|c|c|}
\hline \multirow{2}{*}{\multicolumn{9}{|c|}{ Panel A: dependent variable is Disability Insurance (DI) only allowance rate }} \\
\hline & & & & & & & & \\
\hline \multirow[t]{2}{*}{$=1$ if multi-term governor } & $1.35^{* *}$ & $2.44^{* * *}$ & $1.10^{*}$ & 1.35 & $1.92^{* *}$ & $3.20^{* * *}$ & $2.52^{* * *}$ & -0.14 \\
\hline & $(0.62)$ & $(0.87)$ & $(0.61)$ & $(0.87)$ & $(0.81)$ & $(1.10)$ & $(0.93)$ & $(1.01)$ \\
\hline \multirow[t]{2}{*}{$=1$ if the previous governor is from the same party } & 0.84 & $2.62^{* * *}$ & 0.33 & 0.74 & $1.74^{* *}$ & 0.90 & 1.12 & 0.99 \\
\hline & $(0.56)$ & $(1.00)$ & $(0.73)$ & $(0.81)$ & $(0.74)$ & $(1.23)$ & $(0.88)$ & $(0.97)$ \\
\hline \multirow[t]{2}{*}{$=1$ if governor cannot run again } & -1.01 & $-2.88^{* * *}$ & -1.15 & $-2.59 * * *$ & -1.24 & $-4.38^{* * *}$ & $-2.76^{* * *}$ & -0.75 \\
\hline & $(0.63)$ & $(0.90)$ & $(0.73)$ & $(0.85)$ & $(0.92)$ & $(1.01)$ & $(1.05)$ & $(1.02)$ \\
\hline \multicolumn{9}{|c|}{ Panel B: dependent variable is concurrent (DI + SSI) allowance rate } \\
\hline \multirow[t]{2}{*}{$=1$ if multi-term governor } & $1.61^{* *}$ & $1.71^{* *}$ & $1.48^{*}$ & $1.80^{*}$ & $2.10^{* *}$ & $3.34^{* * *}$ & $2.32^{* * *}$ & 0.02 \\
\hline & $(0.65)$ & $(0.85)$ & $(0.78)$ & $(0.92)$ & $(0.93)$ & $(1.08)$ & $(0.85)$ & $(1.20)$ \\
\hline \multirow[t]{2}{*}{$=1$ if the previous governor is from the same party } & 0.21 & 1.38 & 0.12 & 0.54 & 1.03 & 0.44 & 0.63 & 0.57 \\
\hline & $(0.53)$ & $(0.86)$ & $(0.73)$ & $(0.83)$ & $(0.72)$ & $(1.03)$ & $(0.81)$ & $(1.09)$ \\
\hline \multirow[t]{2}{*}{$=1$ if governor cannot run again } & $-1.67^{* * *}$ & $-2.21^{* *}$ & $-1.76^{* *}$ & $-3.02^{* * *}$ & $-1.79^{*}$ & $-3.51^{* * *}$ & $-2.70^{* * *}$ & -0.79 \\
\hline & $(0.62)$ & $(0.92)$ & $(0.81)$ & $(0.86)$ & $(0.97)$ & $(0.94)$ & $(0.98)$ & $(1.19)$ \\
\hline Observations & 745 & 265 & 329 & 371 & 317 & 144 & 368 & 287 \\
\hline
\end{tabular}

Heteroskedasticity and autocorrelation (4 lags) robust standard errors at the state level in parentheses. Coefficients that are significant at the .10 [.05] (.01) are marked with *[******). Regressions all include additional controls for state marriage rates and age-adjusted state death rates. 
Table 8 Estimates of differences in allowance rates by gubernatorial term length for three different time periods: 1982-86, 1987-92, 1993-00

\begin{tabular}{|c|c|c|c|c|}
\hline & (1) & (2) & (3) & (4) \\
\hline Dependent variable & $\begin{array}{l}\text { Disability } \\
\text { Insurance (DI) } \\
\text { allowance } \\
\text { rate (in \%) }\end{array}$ & $\begin{array}{l}\text { Concurrent } \\
\text { (DI + SSI) } \\
\text { allowance } \\
\text { rate (in \%) }\end{array}$ & $\begin{array}{l}\text { Disability } \\
\text { Insurance (DI) } \\
\text { log-applications } \\
\text { (in \%) }\end{array}$ & $\begin{array}{l}\text { Concurrent } \\
\text { (DI + SSI) } \\
\text { log-applications } \\
\text { (in \%) }\end{array}$ \\
\hline \multirow[t]{2}{*}{$=1$ if multiterm in 1982-85 } & 0.70 & 0.55 & -0.47 & $-5.60^{*}$ \\
\hline & $(1.23)$ & $(1.45)$ & $(2.54)$ & $(3.39)$ \\
\hline \multirow[t]{2}{*}{$=1$ if multiterm in 1987-92 } & $1.16^{*}$ & $1.92^{* * *}$ & -0.06 & 0.56 \\
\hline & $(0.67)$ & $(0.68)$ & $(1.46)$ & $(1.82)$ \\
\hline \multirow[t]{2}{*}{$=1$ if multiterm in 1993-00 } & $1.93^{* * *}$ & $1.76^{* *}$ & -1.25 & -1.05 \\
\hline & $(0.71)$ & $(0.69)$ & $(1.79)$ & $(2.15)$ \\
\hline State FE & Y & Y & Y & Y \\
\hline Year FE & Y & Y & Y & Y \\
\hline Clustered standard errors & Y & Y & Y & Y \\
\hline Estimation method & OLS & OLS & OLS & OLS \\
\hline Observations & 745 & 745 & 745 & 745 \\
\hline R-squared & 0.796 & 0.730 & 0.994 & 0.992 \\
\hline
\end{tabular}

Heteroskedasticity and autocorrelation (4 lags) robust standard errors at the state level in parentheses. Coefficients that are significant at the $.10[.05](.01)$ are marked with $\left.\left.{ }^{*}{ }^{* *}\right]^{* * *}\right)$. Regressions all include additional controls for state marriage rates and age-adjusted state death rates.

rates (Table 9). Governors appear to be influencing allowance rates only when the DDS's decision process becomes more lax and allowance rates increase.

\section{Conclusions}

In this paper we exploit the conflicting incentives for both parties involved in the management of the disability system. On one side, the federal government has an interest in reducing costs, while on the other side, state governors have a vote-buying incentive to increase caseloads. Given that governors want to minimize costs with respect to their own social programs, they have an interest to have marginal individuals receive federal disability funding. The removal of these individuals from the ranks of the unemployed helps change perceptions about the state economic performance, thus affecting a governor's re-election prospects.

Our results provide fairly strong evidence that governors in their second and subsequent terms allow higher acceptance rates for federal Disability Insurance (DI). We believe this inefficiency is due to the inherently imperfect principal-agent situation set up the by the administration of DI. In particular, because the federal government funds DI but to a large extent leaves the management and administration to state government, there is broad scope for gubernatorial discretion to influence the allowance rates. The irony of such a scenario is that the monitoring by the Social Security Administration (SSA) actually may serve to inform governors about the extent to which they can costlessly increase DI. The evidence presented here suggests that the same governors, over time, might increase their allowance rates once they learn how much room they have to increase the rates.

We also provide some evidence confirming the vote-buying use of DI by comparing governors who have a greater incentive to use DI as a political tool. In particular, we find that governors of states with higher than average unemployment rates have larger effects in their first term. Moreover, governors who are restricted in their ability to pass social 
Table 9 Estimates of differences in allowance rates by gubernatorial term length between 2001 and 2013

\begin{tabular}{|c|c|c|c|c|c|c|c|c|}
\hline & (1) & (2) & (3) & (4) & (5) & (6) & (7) & (8) \\
\hline & \multicolumn{4}{|c|}{ Disability Insurance (DI) } & \multicolumn{4}{|c|}{ Concurrent (DI + SSI) } \\
\hline & \multicolumn{2}{|c|}{ Allowance rates } & \multicolumn{2}{|c|}{ Log-applications } & \multicolumn{2}{|c|}{ Allowance rates } & \multicolumn{2}{|c|}{ Log-applications } \\
\hline \multirow[t]{2}{*}{$=1$ if multi-term governor } & -1.20 & -0.20 & 1.25 & $-3.69^{* *}$ & -1.11 & -0.16 & -0.58 & -1.09 \\
\hline & $(0.92)$ & $(1.45)$ & $(1.50)$ & $(1.86)$ & $(0.95)$ & (1.38) & $(1.84)$ & (2.59) \\
\hline \multirow[t]{2}{*}{$=1$ if governor cannot run again } & 0.50 & -1.49 & -0.01 & 1.55 & 0.60 & -1.83 & -0.84 & -0.57 \\
\hline & $(1.12)$ & $(1.67)$ & (1.78) & $(2.47)$ & (1.14) & $(1.70)$ & (2.45) & (3.39) \\
\hline \multirow[t]{2}{*}{ Constant } & $45.62^{* * *}$ & $53.89^{* * *}$ & $974.42^{* * *}$ & $909.44^{* * *}$ & $28.60^{* * *}$ & $34.67^{* * *}$ & $966.37^{* * *}$ & $888.60^{* * *}$ \\
\hline & $(1.16)$ & $(0.84)$ & $(4.77)$ & (2.42) & $(0.88)$ & $(0.72)$ & (2.94) & $(2.52)$ \\
\hline Year FE & Y & Y & Y & Y & Y & Y & Y & Y \\
\hline State FE & Y & $N$ & Y & $N$ & Y & N & Y & $N$ \\
\hline Governor FE & $N$ & Y & $\mathrm{N}$ & Y & N & Y & $N$ & Y \\
\hline Estimation method & OLS & OLS & OLS & OLS & OLS & OLS & OLS & OLS \\
\hline R-squared & 0.720 & 0.881 & 0.996 & 0.998 & 0.703 & 0.883 & 0.992 & 0.996 \\
\hline Observations & 618 & 618 & 618 & 618 & 618 & 618 & 618 & 618 \\
\hline
\end{tabular}

Based on 2001-2013 data file SSA-SA-MOWL found on www.data.gov. All regressions include year fixed effects, and either state or governor fixed effects. With governor fixed effect the standard errors (in parentheses) are clustered at the governor level, with state fixed effects the standard errors are robust to heteroskedasticity and autocorrelation (4 lags). Coefficients that are significant at the $.10[.05](.01)$ are marked with *[**](***). 
welfare programs (either because of political institutions or a split with the legislature) have higher DI allowance rates after the first term. This is consistent with our model of learning and also suggests that there may indeed be some costs to using DI as a vote-buying mechanism.

The results of this paper provide some insight into the ways in which DI administration can be responsible for reduced labor force participation. In a world with perfect information and monitoring, governors could not use disability insurance as a means of vote buying because individuals who were not sufficiently disabled would not be allowed onto the DI rolls. This paper identifies a specific mechanism for how misclassifications and state inconsistencies may underlie misuses of social welfare program by political figures. The average estimates presented in this paper account for about 3 percent of the DI rise and 5 percent of the concurrent DI and SSI rise over the two-decade time period examined in this paper ${ }^{26}$. However, much of the difference occurred over the same time period as the rise in DI rolls suggesting that this political effect may be particularly relevant for the rise in DI and its implications for labor force participation. Moreover, while we identify governors as a source for the politicization of DI, there may be other ways in which state politicians exploit the inherent principle-agent problem set up by the administration of the federal DI programs.

There are a number of caveats worth noting. First, although we identify a potential source of inefficiencies due to the federal-state, principal-agent problem, we cannot determine whether higher or lower allowance rates would be optimal. Second, although we underscore a labor-market spillover, in terms of increased allowance rates reducing the total number of employable individuals, this does not directly imply changes in the labor force participation rate. In particular, although the natural implication of gubernatorial motivations to relax allowance standards would be to reduce the unemployment rate both by reducing the number of people seeking work and the number of people in the labor force, the specific relationship between political motivations and labor force participation rates is left as an area for future research.

Overall, the changes we find are both significant and substantial. Unfortunately, we are not able to make strong statements about the social welfare impact of this politicization of DI allowances because we have little information about who is being allowed onto the rolls. If governors are simply providing some form of social insurance or long-term unemployment insurance for individuals who cannot work and might otherwise suffer severe financial hardship then this use of DI to provide a stop-gap safety net may be net-beneficial. On the other hand, if individuals who would otherwise be employed or actively seeking employment are entering DI, then the program may be quite socially costly. The social welfare implications of the rise in DI rolls and its relationship to this particular mechanism for that rise are therefore left as an area of future research. However, the results provide a cautionary tale for governments seeking to reduce costs from administration. Monitoring in the form of low-cost, non-credible threats is not simply ineffective but may actually be counter-productive. In this case, the monitoring system could facilitate misuse of the system and higher DI rolls, likely far outweighing the costs needed to more effectively monitor state determination services. Thus we would recommend minimizing the principal-agent problem through either federalization of DI or a more strict monitoring system with credible, costly penalties. 


\section{Endnotes}

${ }^{1}$ Even popular guides such as Nolo's Guide (Morton 2004) discuss the possibility that DDS directors may be influenced by political concerns and thus amenable to more lenient allowance policies. In addition, several reports by the Social Security Advisory Boards express concern over this conflict of interest.

${ }^{2}$ Cohen and King (2004) find that when the state unemployment is lower than the national average, governors lose political capital and face worse approval ratings. Approval ratings are important not only because they are a key indication of re-election prospects (King 2001) but also because they expand the executive's ability to set their own policy agenda (Canes-Wrone and De Marchi 2002).

${ }^{3}$ Honig (2013) finds that Democratic governors are associated with higher allowance rates.

${ }^{4}$ There is also some evidence that learning within party lines tends to be faster.

${ }^{5}$ In particular, there is evidence that political institutions matter for policy outcomes. In addition, whether an official is appointed or elected does impact the performance of these officials. See Besley and Case (2003) for an overview on political institutions and expenditures and see for example Peltzman (1992) on vote buying behavior.

${ }^{6}$ For example, Bound (1989) finds only small disincentive effects from DI. In contrast, Gruber and Kubik (1997) and Autor and Duggan (2003), find a significant effect on labor force participation which appears concentrated among the low-skilled.

${ }^{7}$ For many people, the true value of disability insurance is not just the monthly income. Individuals covered under disability insurance are also entitled to Medicare (for DI recipients after a 2 year waiting period) and Medicaid (for SSI recipients).

${ }^{8}$ In fact, the program functions on a credit system which takes account of both how long an individual worked and the time period an individual worked. The number of work credits needed for disability benefits depend on the age of disability.

${ }^{9}$ Social Security Administration Disability Insurance "Red Book," emphasis added.

${ }^{10}$ It bears mentioning that the substantial gainful activity earnings restrictions only refer to money obtained from working and does not restrict income from investments. Thus a disabled individual may have income independent of his or her DI benefits.

${ }^{11}$ This liberalization resulted in greater consideration of mental illness, increased weight placed on symptoms such as pain, and acceptance of diagnoses and evidence from personal physicians of applicants, among other changes. For greater discussion on the effects of liberalization, see Autor and Duggan (2003).

${ }^{12} \mathrm{~A}$ detailed discussion of the original and current structure of the DI program is available in Social Security Advisory Board (2001).

${ }^{13}$ Court cases include Schisler v. Bowen, 787 F. Supp. 76 (2 Cir.1986), which dealt with treating source opinion, and Hyatt v. Heckler, 579 F. Supp. 985 (4 Cir. 1986), which dealt with assessment of pain.

${ }^{14}$ GAO Report to Senator Jim Sasser (General Accounting Office Report to Senator Jim Sasser 1985).

${ }^{15}$ See Finnegan v. Mathews and Patti v. Schweiker.

${ }^{16}$ For detailed discussion of the response of various circuit courts to SSA standards as well as comparison of appeals rates, see Haire and Lindquist (1997).

${ }^{17}$ State DDS performance and compliance with federal policy is measured by the findings of the QARs. Only Group I deficiencies (a decisional deficiency with sufficient documentation to support an opposite decision, or a documentation deficiency where the medical documentation is not sufficient to support any disability decision) are used in the calculation of performance accuracy, provided that the DDS also failed to meet processing time standards for either Title II or Title XVI.

${ }^{18}$ Social Security Administration State-level disability data between 2001 and 2013 were downloaded from www.data.gov. The file is named SSA-SA-MOWL.

${ }^{19}$ It turns out that 2001 represents also the year where the trend in allowance rates reversed. 
${ }^{20}$ The Director of Disability Determination Services is typically appointed by the governor and approved by the legislature. The SSA has no official input into the nomination or appointment of these individuals. Some states have considered this office sufficiently important that the Director of DDS sits on the governor's cabinet.

${ }^{21}$ We also tried specification that use year in office as the main independent variable but in line with the constraints faced by governors the entire effect is driven by changes in the term.

${ }^{22}$ Rupp and Stapleton (1995), and Rupp (2012), and Strand (2002) provide evidence that demographic and health factors shape allowance rates.

${ }^{23}$ Coe et al. (2011) analyze factors that shape application rates.

24 We use the changes in the number of beneficiaries because the supplements do not contain information about applicants or allowed.

${ }^{25}$ The specifications reported in Table 7 use individual subgroups for clarity of discussion. Results from a pooled regression are similar and there are no significant interactive effects between the subgroups (although there are likely too few observations to get sufficient statistical power to identify any interactive effects).

${ }^{26}$ We derive this number multiplying the multi-term effect by the application rates, assuming there are no general equilibrium effects on applications.

\section{A Online appendix}

\section{A.1 Basic setup of the model}

To begin, suppose the governor has utility $U(x)$, where $x=a-a^{s s a}$ and represents the difference between the allowance rate set by the governor $(a)$ and SSA's desired allowance rate $\left(a^{s s a}\right)$. SSA observes $x$. SSA can take one of three actions: i) do nothing, ii) send a warning $(s=1)$, and iii) impose technical and management assistance or completely take over the administration (in short take over, $t=1$ ). To decide which action to take, SSA follows these rules:

- send a warning if $x>c-\Delta$ (i.e. define a variable such that $s=1(x>c-\Delta)$ )

- take over disability determination if $x>c$ (i.e. define a variable such that $t=1(x>c))$.

In these rules $c$ represents the cost to the SSA of taking over any DDS and $\Delta$ is the amount by which SSA shades the true costs of takeover in order to ensure compliance. For illustrative purposes we will treat $\Delta$ as exogenously given ${ }^{27}$. Assume that governors know $\Delta$, but don't know $c^{28}$. That is, we assume that governors know how much SSA will shade by but they do not know the true cost of takeover. Also, assume that if $x>c$ governors utility is zero (i.e. $U(x)=0$ for) the period and any period after. That is governors receive zero utility in this period and future periods if SSA takes over and as such governors will always avoid setting $x>c$.

In a one period model the governor weights the utility gain from setting a higher acceptance rate against the increase in the probability of takeover ${ }^{29}$. In a two period model, however, information is transmitted based on the SSA's action in the previous period. The governors will therefore maximize their utility over both periods, i.e.

$$
\begin{aligned}
\max _{x_{0}, x_{10}, x_{11}} U\left(x_{0}, x_{10}, x_{11}\right)= & \operatorname{Pr}\left(t_{0}=0\right) U\left(x_{0}\right)+\operatorname{Pr}\left(t_{0}=0, t_{1}=0, s=0\right) U\left(x_{10}\right) \\
& +\operatorname{Pr}\left(t_{0}=0, t_{1}=0, s=1\right) U\left(x_{11}\right) .
\end{aligned}
$$

where $x_{0}$ is the difference between SSA's desired allowance rate and the allowance rate set by the governor at time $\tau=0, x_{10}$ is the difference between SSA's desired allowance rate 
and the allowance rate set by the governor at time $\tau=1$ if the governor does not receive a warning, and $x_{11}$ difference between SSA's desired allowance rate and the allowance rate set by the governor at time $\tau=0$ if the governor receives a warning.

\section{A.2 Solving the governor's maximization problem}

Suppose that $c$ has a known distribution, $F(c)$, which admits a density $f(c)$. Substituting in the distribution function for the probabilities, the expected utility in Equation 5 simplifies to:

$$
\left[1-F\left(x_{0}\right)\right] U\left(x_{0}\right)+\left[1-F\left(x_{10}\right)\right] U\left(x_{10}\right)+\left[F\left(x_{0}+\Delta\right)-F\left(x_{11}\right)\right] U\left(x_{11}\right)
$$

Suppose the governor maintains the administration of the disability program (i.e. $t_{0}=$ $0, t_{1}=0, s=1$ ) and he received a warning, then $x_{11}$ is implicitly defined by:

$$
\arg \max _{x_{1}} P\left(c>x_{11} \mid c>x_{0}, s\right) U(x)=\left(1-F\left(x_{11} \mid x_{0}<c<x_{0}+\Delta\right)\right) U\left(x_{11}\right)
$$

The first order condition from Equation 7 is:

$$
\left(1-F\left(x_{11} \mid x_{0}<c<x_{0}+\Delta\right)\right) U_{1}\left(x_{11}, \alpha\right)-f\left(x_{11} \mid x_{0}<c<x_{0}+\Delta\right) U\left(x_{11}\right)=0
$$

or more simply:

$$
\left(F\left(x_{0}+\Delta\right)-F\left(x_{11}\right)\right) U_{1}\left(x_{11}\right)-f\left(x_{11}\right) U\left(x_{11}\right)=0
$$

In a parallel manner the governor's strategy in the state of the world where there is no warning at time (i.e. $t_{0}=0, t_{1}=0, s=0$ ) is implicitly defined by the first order condition:

$$
\left(1-F\left(x_{10}\right)\right) U_{1}\left(x_{10}\right)-f\left(x_{10}\right) U\left(x_{10}\right)=0
$$

Let $x_{10}^{*}$ and $x_{11}^{*}$ be the solutions to these two maximization problems. We can then rewrite Equation 6 as:

$$
\left[1-F\left(x_{0}\right)\right] U\left(x_{0}\right)+\left[1-F\left(x_{10}^{*}\right)\right] U\left(x_{10}^{*}\right)+\left[F\left(x_{0}+\Delta\right)-F\left(x_{11}^{*}\right)\right] U\left(x_{11}^{*}\right)
$$

with corresponding first order condition:

$$
\begin{aligned}
0= & {\left[1-F\left(x_{0}\right)\right] U_{1}\left(x_{0}\right)-f\left(x_{0}\right) U\left(x_{0}\right) } \\
& +\left\{\left[1-F\left(x_{10}^{*}\right)\right] U_{1}\left(x_{10}^{*}\right)-f\left(x_{10}^{*}\right) U\left(x_{10}^{*}\right)\right\} x_{10}^{\prime *}\left(x_{0}\right) \\
& +\left\{\left[F\left(x_{0}+\Delta\right)-F\left(x_{11}^{*}\right)\right] U_{1}\left(x_{11}^{*}\left(x_{0}\right)\right)-f\left(x_{11}^{*}\right) U\left(x_{11}^{*}\right)\right\} x_{11}^{\prime *}\left(x_{0}\right) \\
& +f\left(x_{0}+\Delta\right) U\left(x_{11}^{*}\right)
\end{aligned}
$$

In Equation 11, $x_{10}^{\prime *}\left(x_{0}\right)$ is the change in the second period solution (without warning) with respect to $x_{0}$, and similarly $x_{11}^{\prime *}\left(x_{0}\right)$ is the change in the second period solution (with a warning) with respect to $x_{0}$.

Note that these first order conditions (Equations 8, 9, and 11) cannot be simultaneously satisfied. If they were all satisfied we would be left with

$$
0=\left[1-F\left(x_{0}\right)\right] U_{1}\left(x_{0}\right)-f\left(x_{0}\right) U\left(x_{0}\right)+f\left(x_{0}+\Delta\right) U\left(x_{11}^{*}\right)
$$

Define $G\left(x_{0}\right)=\left[1-F\left(x_{0}\right)\right] U_{1}\left(x_{0}\right)-f\left(x_{0}\right) U\left(x_{0}\right)$. Equation 12 then implies that $G\left(x_{0}\right)<0$. However, we have assumed $G\left(x_{10}^{*}\right)=0$. Because of the regularity condition $G(z)$ is decreasing, implying that $x_{10}^{*}<x_{0}$, which cannot be optimal. Governors will never set $x_{1}<x_{0}$ if there was no takeover in the initial period (i.e., governors should always set $x_{1} \geq x_{0}$ ). 
Consider a case where governors choose the interior solution if they do not receive a warning, so that $G\left(x_{10}^{*}\right)=0$. If there is a warning instead, governors pursue the safest strategy and maintain the same acceptance rate in the second period (i.e. if $s=1$, then $\left.x_{11}^{*}=x_{0}\right)$. In this situation, we can rewrite the first order condition:

$$
0=G\left(x_{0}\right)+\left[F\left(x_{0}+\Delta\right)-F\left(x_{0}\right)\right] U_{1}\left(x_{0}\right)-f\left(x_{0}\right) U\left(x_{0}\right)+f\left(x_{0}+\Delta\right) U\left(x_{0}\right)
$$

In order for Equation 13 to hold, $G\left(x_{0}\right)+\left[F\left(x_{0}+\Delta\right)-F\left(x_{0}\right)\right] U_{1}\left(x_{0}\right)-f\left(x_{0}\right)$ $U\left(x_{0}\right)<0$. Since $x_{10}^{*}>x_{0}$ and $G(z)$ is decreasing in $z$, we know that $G\left(x_{0}\right)>0$. This implies that $F\left(x_{0}+\Delta\right)-F\left(x_{0}\right) U_{1}\left(x_{0}\right)-f\left(x_{0}\right) U\left(x_{0}\right)<0$.

Note however that this implies that:

$$
\begin{gathered}
G\left(x_{0}\right)-\left|\left[F\left(x_{0}+\Delta\right)-F\left(x_{0}\right)\right] U_{1}\left(x_{0}\right)-f\left(x_{0}\right) U\left(x_{0}\right)\right|>0 \Rightarrow \\
G\left(x_{0}\right)-\left(-\left\{\left[F\left(x_{0}+\Delta\right)-F\left(x_{0}\right)\right] U_{1}\left(x_{0}\right)-f\left(x_{0}\right) U\left(x_{0}\right)\right\}\right)>0 \Rightarrow \\
G\left(x_{0}\right)+\left[F\left(x_{0}+\Delta\right)-F\left(x_{0}\right)\right] U_{1}\left(x_{0}\right)-f\left(x_{0}\right) U\left(x_{0}\right)>0
\end{gathered}
$$

Thus there does not exist an interior solution where after a warning the governor will set the acceptance rate at the same level. Intuitively this results indicates that because governors know they still have some room to increase their acceptance rates and the warning itself does not impose any costs (so getting another warning without a takeover is costless), it is not optimal for them to simply maintain the status quo when given a warning.

Next, consider a case where governors choose the optimal $x_{1}$ if they receive a warning (i.e. the first order condition for $x_{11}^{*}$ is satisfied). If there is no warning, governors simply increase by $\Delta$ (i.e. $x_{10}^{*}=x_{0}+\Delta$ ). Note that since $\Delta$ is known, and the strategy of the SSA is known, governors know they can safely increase by $\Delta$ and still avoid takeover. Additionally, $G\left(x_{11}^{*}\right)>0$. Since we know that $x_{11}^{*}>x_{0}$, this implies that $G\left(x_{0}\right)>0$. The first order conditions can then be written as:

$$
\begin{aligned}
& 0=G\left(x_{0}\right)+G\left(x_{0}+\Delta\right)+f\left(x_{0}+\Delta\right) U\left(x_{11}^{*}\right) \\
& 0=\left[F\left(x_{0}+\Delta\right)-F\left(x_{11}^{*}\right)\right] U_{1}\left(x_{11}^{*}\right)-f\left(x_{11}^{*}\right) U\left(x_{11}^{*}\right)
\end{aligned}
$$

The first condition can be satisfied if $G\left(x_{0}+\Delta\right)$ is sufficiently negative. In this case, governors will always choose $x_{11}>x_{0}$ and the warning by the SSA simply dictates the magnitude of the increase ${ }^{30}$.

Competing interests

The IZA Journal of Labor Policy is committed to the IZA Guiding Principles of Research Integrity. The authors declare that they have observed these principles.

\footnotetext{
Acknowledgments

We would like to thank the editor David Neumark for his numerous and insightful comments that improved the paper tremendously. This paper was submitted to the IZA Journal of Labor Policy's call for papers on "Social Security Disability Benefits: Finding Alternatives to Benefit Receipt." Two special editors, David Wittenburg and Gina Livermore, were sponsored by the University of New Hampshire's Rehabilitation, Research, and Training Center on Employment Policy and Measurement, funded by the U.S. Department of Education (ED), National Institute on Disability and Rehabilitation Research (cooperative agreement no. H133B100030). Their comments do not necessarily represent the policies of ED or any other federal agency (Edgar, 75.620 (b)). The authors are solely responsible for all views expressed.

Responsible editor: David Neumark

Author details

${ }^{1}$ National Bureau of Economic Research, London School of Economics, London, UK. ${ }^{2}$ University of Essex, Colchester, UK.

${ }^{3}$ Collegio Carlo Alberto, Moncalieri Torino, Italy. ${ }^{4}$ IZA, Bonn, Germany. ${ }^{5}$ Netspar, The Netherlands.
} 


\section{References}

Autor DH, Duggan MG (2003) The rise in the disability rolls and the decline in unemployment. Q J Econ 118(1):157-205 Berkowitz E (1987) Disabled Policy. Cambridge University Press, Cambridge

Besley T, Case A (1995a) Does electoral accountability affect economic policy choices? Evidence from gubernatorial term limits. Q J Econ 110(3):769-98

Besley, T, Case A (1995b) Incumbent behavior: vote-seeking, tax-setting, and yardstick competition. Am Econ Rev 85(1):25-45

Besley T, Case A (2003) Political institutions and policy choices: evidence from the United States. J Econ Lit 41 (1):7-73

Bound J (1989) The health and earnings of rejected disability insurance applicants. Am Econ Rev 79(3):482-503

Canes-Wrone B, DeMarchi S (2002) Presidential approval and legislative success. J Polit 64(2):491-509

Coe NB, Haverstick K, Munnell AH, Webb A (2011) What explains state variation in SSDI application rates? CRR WP:2011-23. Boston

Cohen JE, King JD (2004) Relative unemployment and gubernatorial popularity. J Pol 66(4):s1267-1282

General Accounting Office Report to Senator Jim Sasser (1985) Current status of the federal/state arrangement for administering the social security disability programs. GAO/HRD-85-71

Gruber J, Kubik JD (1997) Disability insurance rejection rates and the labor supply of older workers. J Publ Econ 64(1):1-23

Haire S, Lindquist S (1997) Social security disability cases in the US Court of Appeals. Judicature 80(5):230-236

Honig D (2013) Denied disability? Try another state: discretion and inequity in eligibility determinations of US federal disability programs. mimeo

Keiser LR (1999) State bureaucratic discretion and the administration of social welfare programs: the case of social security disability. J Publ Admin Res Theor 9(1):87-106

Keiser, LR (2001) Street-level bureaucrats, administrative power and the manipulation of federal social security disability programs. State Polit Pol Q 1(2):144-164

Keiser LR (2010) Understanding Street-Level Bureaucrats' Decision Making: Determining Eligibility in the Social Security Disability Program. Public Administration Review 70(2):247-257

King JD (2001) Incumbent popularity and vote choice in gubernatorial elections. J Polit 63(2):585-592

Morton DA (2004) Nolo's guide to social security disability, getting and keeping your benefits. Ilona Bray, Berkeley

Peltzman, S (1992) Voters as fiscal conservatives. Q J Econ 107(2):327-361

Rupp K (2012) Factors affecting initial disability allowance rates for the disability insurance and supplemental security income programs: the role of the demographic and diagnostic composition of applicants and local labor market conditions. Soc Secur Bull 72(4):11-35

Rupp K, Stapleton D (1995) Determinants of the growth in the social security administration's disability programs-an overview. Soc Secur Bull 58(4):43-70

Schneider R (1996) Role for the Courts: treating Physician Evidence in Social Security Disability Determinations, University of Chicago Law School Roundtable 3:391-395

Social Security Advisory Board (2001). Disability Decision Making: Data And Materials. Technical Report

Stapleton DC, Pugh MD (2001) Evaluation of SSA's disability quality assurance (QA) processes and development of QA options that will support the long-term management of the disability program: final report. Report to the Social Security Administration. The Lewin Group, Washington, DC

Strand A (2002) Social security disability programs: assessing the variation in allowance rates. Working Paper Series, Number 98

United States General Accounting Office (1978) A plan for improving the federal disability determination process by bringing it under complete federal management should be developed, Washington, DC. HRD-78-146

U.S. Social Security Administration. http://www.ssa.gov/policy/docs/chartbooks/disability_trends/sect04.html

Wolfers J (2007) Are voters rational? Evidence from gubernatorial elections

doi:10.1186/2193-9004-3-16

Cite this article as: Iyengar and Mastrobuoni: The political economy of the disability insurance: theory and evidence of gubernatorial learning. IZA Journal of Labor Policy 2014 3:16.

\section{Submit your manuscript to a SpringerOpen ${ }^{\circ}$ journal and benefit from:}

- Convenient online submission

Rigorous peer review

- Immediate publication on acceptance

- Open access: articles freely available online

- High visibility within the field

- Retaining the copyright to your article

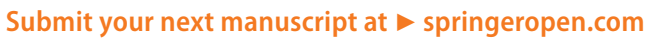

